\title{
Prosodically conditioned strengthening and vowel-to-vowel coarticulation in English
}

\author{
Taehong Cho* \\ Max Planck Institute for Psycholinguistics, Postbus 310, 6500 AH Nijmegen, The Netherlands
}

Received 25 October 2001; received in revised form 26 May 2003; accepted 20 June 2003

\begin{abstract}
The goal of this study is to examine how the degree of vowel-to-vowel coarticulation varies as a function of prosodic factors such as nuclear-pitch accent (accented vs. unaccented), level of prosodic boundary (Prosodic Word vs. Intermediate Phrase vs. Intonational Phrase), and position-in-prosodic-domain (initial vs. final). It is hypothesized that vowels in prosodically stronger locations (e.g., in accented syllables and at a higher prosodic boundary) are not only coarticulated less with their neighboring vowels, but they also exert a stronger influence on their neighbors. Measurements of tongue position for English /a i/ over time were obtained with Carsten's electromagnetic articulography. Results showed that vowels in prosodically stronger locations are coarticulated less with neighboring vowels, but do not exert a stronger influence on the articulation of neighboring vowels. An examination of the relationship between coarticulation and duration revealed that (a) accent-induced coarticulatory variation cannot be attributed to a duration factor and (b) some of the data with respect to boundary effects may be accounted for by the duration factor. This suggests that to the extent that prosodically conditioned coarticulatory variation is duration-independent, there is no absolute causal relationship from duration to coarticulation. It is proposed that prosodically conditioned $\mathrm{V}$-to- $\mathrm{V}$ coarticulatory reduction is another type of strengthening that occurs in prosodically strong locations. The prosodically driven coarticulatory patterning is taken to be part of the phonetic signatures of the hierarchically nested structure of prosody.
\end{abstract}

(C) 2003 Elsevier Ltd. All rights reserved.

Keywords: Prosody; Vowel-to-vowel coarticulation; Prosodic boundary; Accent; Strengthening; English; Coarticulatory resistance; Prosodic structure

*Tel.: + 31-24-3521375; fax: +31-24-3521213.

E-mail address: taehong.cho@mpi.nl (T. Cho). 


\section{Introduction}

When sounds are produced in connected speech, their physical realizations are conditioned by segmental context, a phenomenon known as coarticulation (e.g., Öhman, 1966; Fowler, 1980; for a review see Farnetani, 1997; Kühnert \& Nolan, 1999). Recent studies have also shown that the phonetic realization of segments varies depending on the prosodic position in which the segments occur-e.g., in pitch-accented vs. non-accented syllables (e.g., de Jong, 1995a; Harrington, Fletcher, \& Roberts, 1995) and at the edges of prosodic constituents vs. inside them (e.g., Edwards, Beckman, \& Fletcher, 1991; Jun, 1993; Fougeron \& Keating, 1997; Keating, Cho, Fougeron, \& Hsu, in press). The present study investigates these two major sources of speech variation (segmental and prosodic contexts), by examining vowel-to-vowel (henceforth V-to-V) coarticulation. Given that segments are strengthened in prosodically strong locations such as in pitch-accented syllables and at the edges of prosodic domains (e.g., Beckman \& Edwards, 1994; de Jong, 1995a; Fougeron \& Keating, 1997; Fougeron, 2001; Cho \& Keating, 2001; Cho, 2002, submitted for publication; Tabain, 2003), this paper investigates (1) whether the vowels $/ \mathrm{i}$ a/ in prosodically strong locations resist coarticulation with neighboring vowels and (2) how V-to-V coarticulatory variations are related to, or influenced by, strengths of articulation that vary with prosodic position.

\subsection{Background}

Coarticulation is a phenomenon in which the articulatory movements required for one gesture are often anticipated (anticipatory coarticulation) or carried over (carryover coarticulation) during the production of an adjacent gesture. The term coarticulatory resistance refers to the degree to which a given segment resists potential interference of neighboring segments (see Farnetani \& Recasens, 1999). Various researchers (e.g., Bladon \& Nolan, 1977; Fowler, 1981; Recasens, 1987; Farnetani, 1990; Farnetani \& Recasens, 1993) have observed that sounds with coarticulatory resistance also exert stronger influence on their neighboring vowels - "they exhibit the least contextual variation and induce the greatest" (Farnetani, 1990, p. 106). This characteristic has been termed "coarticulatory aggression" (Fowler \& Saltzman, 1993).

Coarticulatory resistance can be found in several contexts. One type can be seen when coarticulation would result in the blurring of phonetic contrasts (Manuel, 1990, 1999). Second, it can be found with inherently strong segments. Here 'strong' can be defined on the basis of sonority. For example, Lindblom (1983) proposed that the degree of coarticulatory resistance is roughly inversely proportional to a segment's degree of sonority. Similarly, Recasens (1984a, b, 1985) and Farnetani (1990) showed an inverse relationship between the degrees of coarticulation and linguopalatal contact associated with lingual consonants.

Third, a number of studies (e.g., Fowler, 1981; De Jong, Beckman, \& Edwards, 1993; de Jong, 1995a) have recently alluded to the possibility that prosodically induced or pragmatically induced articulatory strengthening may also bring about coarticulatory resistance. Here the term strengthening can be defined as an increase in the spatio-temporal magnitude of gestures such that, for example, consonants are articulated with extreme and longer constrictions, and vowels are articulated with their assumed targets fully realized and for a longer period of time. However, only a few studies have investigated coarticulatory effects in combination with high-level prosodic 
conditions (e.g., de Jong, et al., 1993; de Jong, 1995a). For example, de Jong (1995a) showed that the coarticulation of $/ \mathrm{t} /$ into a following $/ \theta /$ is reduced when $/ \mathrm{t} /$ occurs in sententially stressed syllables (i.e., in nuclear pitch-accented syllables). Based on this, de Jong argued that the result finding less coarticulation was due to hyperarticulation under accent, which as a result, enhances the distinctiveness of segments. This study, however, was limited to the accent effects on C-to-C coarticulation, without considering prosodic boundary factors. Another study looking at coarticulation and prosodic conditions can been found in Fowler's (1981) examination of word level (or lexical) stress effects on V-to-V coarticulation. Results showed that stressed vowels are less coarticulated with neighboring vowels than unstressed vowels are-i.e., neighboring vowels have less coarticulatory impact on stressed vowels than on unstressed vowels. Magen (1997) also showed long distance stress effects on V-to-V coarticulation on a word level. (See Beddor, Harnsberger, \& Lindermann, 2002 for language-specific effects of stress on V-to-V coarticulation.) Again, these studies were limited to word level stress effects without considering higher level prosodic factors. Thus we have a very limited understanding of V-to-V coarticulatory effects under high-level prosodic conditions such as sentential stress (or accent) and prosodic phrasal boundaries (domain initial and domain final). These three factors are examined in this study.

\subsubsection{Prosodically strong locations and strengthening}

The first strengthening effect comes from nuclear pitch-accent (henceforth accent), which refers to the degree of distinctiveness or prominence of a given linguistic unit relative to the rest of the phrase or sentence. Distinctiveness can be achieved through a variety of acoustic and articulatory parameters showing extreme articulation (e.g., larger articulatory magnitude and longer duration; e.g., Beckman \& Edwards, 1994; de Jong, 1991, 1995a, b; Cho, submitted for publication).

The second well-known prosodically conditioned positional effect is seen with domain-final or preboundary lengthening. Here, more extreme lengthening occurs at the end of higher prosodic domains (e.g., the Intonational Phrase) as compared to lower prosodic domains (e.g., the syllable) (e.g., Klatt, 1975; Edwards et al., 1991; Wightman, Shattuck-Hufnagel, Ostendorf, \& Price, 1992; see Byrd \& Saltzman, 2003 for computational simulations of the dynamics of boundary-adjacent lengthening). In addition to the lengthening effect, it has been suggested that domain-final vowels may also be produced with greater articulatory magnitude. This results in a greater V-to-C displacement between a domain-final vowel and a domain-initial consonant (Fougeron \& Keating, 1997). Data reported in Edwards et al. (1991) also suggest that domain-final vowels can be more extreme (e.g., with greater jaw lowering), as compared to domain-medial ones, especially when vowels are unaccented (see Cho, submitted for publication, for similar results based on lip aperture data). Thus, the preboundary phonetic phenomenon can be thought of as strengthening, rather than simply as lengthening.

Finally, the third strengthening effect occurs domain-initially (in postboundary positions). For example, a recent series of EPG studies have shown that consonants are generally produced with greater articulatory magnitude (as measured by linguopalatal contact) in domain-initial positions at each prosodic level (e.g., Word, Intermediate Phrase (=ip), Intonational Phase (=IP)) than in domain-medial positions at the same level (e.g., Fougeron \& Keating, 1997; Fougeron, 2001; Cho \& Jun, 2000; Cho \& Keating, 2001; see Keating et al., in press, for a cross-linguistic comparison). Some studies have also suggested that vowels may be more strongly articulated domain-initially than domain-medially, as reflected in larger lip aperture in a \#CV context in English (Cho, 2002, 
submitted for publication) or a greater degree of constriction for French $/ \mathrm{i} /$ in a $/ \mathrm{p} \#$ _p/ context (Fougeron, 2001).

In short, previous studies point to three kinds of prosodically determined locations where segments may be strongly articulated. One is in accented syllables, another is in domain-final positions, and the third is in domain-initial positions. It is in these three prosodically strong positions that $\mathrm{V}$-to- $\mathrm{V}$ coarticulation is examined in this paper. ${ }^{1}$

\subsection{Hypotheses}

As discussed above, previous studies have suggested that vowels in lexically stressed syllables may resist coarticulation with neighboring vowels. The present study extends this to sentential level stress or accent and tests the following hypothesis:

H1 (Accent-induced coarticulatory reduction). Accented vowels are coarticulated less with neighboring vowels than unaccented vowels are.

Further, this study examines whether vowels at the edges of prosodic domains also resist coarticulation by testing the following hypothesis:

H2 (Boundary-induced coarticulatory reduction). Vowels undergo less coarticulation at domainedges than domain-medially, such that there is less V-to-V coarticulation across a higher prosodic boundary than across a lower prosodic boundary.

This study also tests whether any observed coarticulatory reduction can be accounted for by the V-to-V interval. Lindblom (1963) suggested that vowel reduction is a coarticulatory process that largely depends on duration. Here shorter durations result in target undershoot and shift vowel articulations toward the articulation of the neighboring segments. Relatedly, Shin (1997) showed that V-to-V coarticulation in VCV sequences in Korean may vary as a function of the intervening consonant's duration: the longer the consonant duration, the less V-to-V coarticulation. Since our coarticulatory data are also based on VCV sequences, it is reasonable to expect that shorter intervals between transconsonantal target vowels would also induce a greater degree of coarticulation. Thus, we also test the following hypothesis:

H3 (Duration-dependent coarticulatory reduction). Degree of V-to-V coarticulation is correlated with the V-to-V interval, such that the smaller the interval, the greater the degree of coarticulation.

\footnotetext{
${ }^{1} \mathrm{CV}$ coarticulation (rather than V-to-V coarticulation) may be more sensitive to strengthening effects because of two opposite articulatory forces, involved with consecutive consonant and vowel gestures, the vocal tract narrowing for $\mathrm{C}$ vs. the vocal tract widening for V. However, in this study, V-to-V coarticulation was chosen because it allows us to examine multiple prosodic factors at the same time: we can simultaneously observe the effects of accent from both encroaching (neighboring) and encroached (target) segments: It also allows us to manipulate the type of prosodic boundary falling between target segments (rather than before or after target segments in the case of CV).
} 

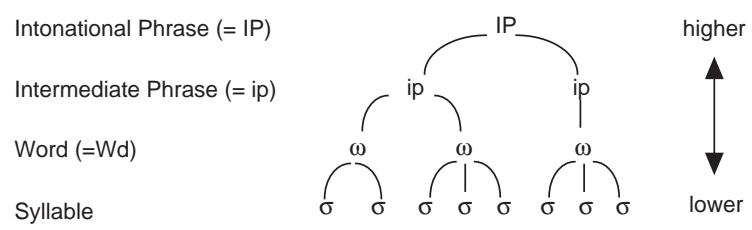

Fig. 1. Prosodic structure of English (after Beckman \& Pierrehumbert, 1986).

Note that for the rest of this paper the term coarticulatory reduction is used to refer to a decrease in $\mathrm{V}$-to- $\mathrm{V}$ coarticulation, whereas the term coarticulatory resistance refers specifically to coarticulatory reduction that is at least partially duration-independent.

Another question to be addressed is whether segments in prosodically strong locations also induce strong coarticulatory effects on neighboring segments. If segments in prosodically strong locations show coarticulatory resistance, we can further predict that they will also have a stronger coarticulatory influence (or aggression) on neighboring segments than those in prosodically weak positions. This leads to an additional hypothesis as follows:

H4 (Accent-induced coarticulatory aggression). Accented vowels have a greater coarticulatory influence on neighboring vowels than unaccented vowels do. ${ }^{2}$

In addition to testing these hypotheses, this study will provide an opportunity to examine V-to- $\mathrm{V}$ coarticulation in terms of its variation as a function of inherent segmental properties. Recasens (1989) noted that coarticulatory effects are generally greater on $/ \mathrm{a} /$ than on $/ \mathrm{i} /$. This is consistent with Lindblom's (1983) observation that the degree of coarticulatory resistance is roughly inversely proportional to the degree of sonority with which segments are intrinsically associated. Given that the open vowel $/ \mathrm{a} /$ is inherently more sonorous than the closed vowel $/ \mathrm{i} /$, the examination of two opposite vowels (/a/ vs. /i/) allows us to make note of the relationship between $\mathrm{V}$-to-V coarticulation and the inherent segmental properties of vowels.

Finally, this study explores how prosodically conditioned coarticulatory variation can be explained under the rubric of the window model (Keating, 1990). This model accounts for coarticulatory phenomena by making phonetic targets vary within a specified range rather than simply having fixed values. Building on the idea that the window is flexible enough to accommodate influences of various linguistic or extralinguistic factors (Guenther, 1995; Guenther, Hampson, \& Johnson, 1998), it will be discussed how the window model can be modified to reflect prosodically conditioned articulatory variation.

\subsection{Prosodic organization}

This paper adopts the model of prosodic structure proposed by Beckman and Pierrehumbert (1986) from which the current English tone and break index (ToBI) system has emerged. (See Selkirk, 1984 and Jun, 1998 for discussion on syntax-based vs. intonation-based prosodic organization.) The prosodic structure is shown in Fig. 1. This figure illustrates a prosodic

\footnotetext{
${ }^{2}$ Note that it was not possible to test the coarticulatory aggression hypothesis with respect to boundary strengths because both encroaching and encroached vowels always occur across a prosodic boundary of the same strength.
} 
hierarchy where lower domains (e.g., syllables) are grouped into immediately higher levels (e.g., words). (Note that the foot, which is generally considered a minimal bracketing unit in assigning stress above the domain Syllable, is not shown in the figure.)

The prosodic structure of speech is also conditioned to some extent by a higher level prominence or stress hierarchy. Stress in a broad sense has been considered the linguistic manifestation of rhythmic structure, varying in degree of prominence across prosodic levels (e.g., Liberman \& Prince, 1977; Beckman, 1986; Hayes, 1989; de Jong et al., 1993; Beckman \& Edwards, 1994). In English, stress can be divided into at least three degrees (see ShattuckHufnagel \& Turk, 1996): no stress or stresses below primary, primary word stress (lexical stress) and sentence stress (nuclear pitch-accent). The degree of stress increases from lexical stress to nuclear pitch-accent. This stress or prominence-based prosodic hierarchy is to some extent linked to the constituent-based prosodic hierarchy, such that the lexically stressed syllable is defined as the head of the word, and the nuclear pitch-accented syllable as the head of the Intermediate Phrase boundary (ip) (see Beckman \& Edwards, 1994).

\section{Method}

\subsection{Speech material and speakers}

An important criterion for building the corpus of this study was to include both prosodic and segmental variables. Each item in the corpus included two test syllables (pre and postboundary), yielding a $\mathrm{C}_{1} \mathrm{~V}_{1} \# \mathrm{C}_{2} \mathrm{~V}_{2}$ sequence (where $\#=$ some prosodic boundary) across two plausible English words. The first and second consonants $\left(\mathrm{C}_{1}, \mathrm{C}_{2}\right)$ were always $/ \mathrm{b} /$, whose articulation is known to interfere minimally with the vocalic lingual articulation. The first and the second vowels $\left(\mathrm{V}_{1}, \mathrm{~V}_{2}\right)$ were either /i/ or /a/, resulting in four pairs: /i\#bi/, /a\#ba/, /i\#ba/, and /a\#bi/. Identical vowel sequences (/i\#bi/, /a\#ba/) allowed us to examine vowel articulation with no contextual influence. On the other hand, the sequences with opposite vowels allowed us to examine coarticulatory effects.

Turning to prosodic variables, the boundary between the test syllables was varied from the Intonational Phrase boundary (IP), to the ip boundary, to the Word boundary (Wd). At the same time, accentuation was manipulated in preboundary and postboundary syllables, resulting in four pairs of accent combinations: ACC\#ACC, ACC\#UNACC, UNACC\#ACC, UNACC\#UNACC. Such a manipulation of prosodic factors yielded three prosodic variables: (a) prosodic boundary between test syllables; (b) accentuation of syllables adjacent to the boundary (accented, unaccented); (c) position-in-domain of test syllables (initial, final).

Six native speakers of American English participated in the experiment. Four speakers were linguistics Ph.D. students at UCLA; one speaker was a postdoctoral researcher; and one was an undergraduate linguistics student at UCLA. To control for variation in rounding in the low vowel, speakers whose dialect lacked the phoneme $/ \mathrm{o} /$ were chosen. They were all trained in producing English sentences according to transcriptions prior to the experiment. Before the actual recording date, each speaker participated in an approximately $2 \mathrm{~h}$ long practice session during which $\mathrm{s} /$ he practiced the sentences in a mini discourse situation to produce the intended renditions as naturally as possible. 
Table 1

A subset of the corpus containing / ba\#ba/ sequence with different prosodic boundaries (IP, ip, Wd) and accentual patterns

\# = Word boundary

(a) ACC.-UNACC .

Prompt: Did you just say "Little Boo bopped the girl last night"?

Target: No, "Little Bah \# bopped the girl"

rendition: $\quad(\mathrm{L}+) \mathrm{H}^{*} \quad \mathrm{~L}-\mathrm{L} \%$

(b) UNACC. -ACC.

Prompt: Did you just say "Little Bah popped the girl last night"?

Target: No, "Little Bah \# bopped the girl"

rendition: $(\mathrm{L}+) \mathrm{H}^{*} \quad \mathrm{~L}-\mathrm{L} \%$

(c) ACC.-ACC.

Target: You know what? Little Bah \# bopped the girl.

rendition: $\quad\left(\mathrm{L}+\mathrm{H}^{*} \quad \mathrm{H}^{*} \quad \mathrm{~L}-\mathrm{L} \%\right.$

(d)UNACC.-UNACC.

Prompt: Did you just say "Big Bah bopped the girl last night"?

Target: No, "Little Bah \# bopped the girl"

rendition : $\left(\mathrm{L}+\mathrm{H}^{*} \quad \mathrm{~L}-\mathrm{L} \%\right.$

\# = Intermediate or Intonational Phrase boundaries (ip or IP)

(e) ACC.-UNACC.

Prompt: Did you say "Little Boo bopped the boy last night"?

Target: No, " Little Bah \# bopped the girl."

rendition 1: $\quad(\mathrm{L}+) \mathrm{H}^{*} \mathrm{~L} \quad(\mathrm{~L}+) \mathrm{H}^{*} \mathrm{~L}-\mathrm{L} \%$

rendition 2: $\quad(\mathrm{L}+) \mathrm{H} * \mathrm{~L}-\mathrm{L} \% \quad(\mathrm{~L}+) \mathrm{H}^{*} \mathrm{~L}-\mathrm{L} \%$

(f) UNACC.-ACC.

Prompt: Did you say "Big Bah popped the girl last night"?

Target: No, " Little Bah \# bopped the girl.

rendition 1: $\quad(\mathrm{L}+) \mathrm{H}^{*} \quad \mathrm{~L}-\quad(\mathrm{L}+) \mathrm{H}^{*} \quad \mathrm{~L}-\mathrm{L} \%$

rendition 2: $\quad(\mathrm{L}+) \mathrm{H}^{*} \quad \mathrm{~L}-\mathrm{L} \% \quad(\mathrm{~L}+) \mathrm{H}^{*} \quad \mathrm{~L}-\mathrm{L} \%$

(g) ACC. $-A C C$.

Prompt: Did you say "Little Boo popped the girl"?

Target: No, " Little Bah \# bopped the girl.

rendition 1: $\quad(\mathrm{L}+) \mathrm{H}^{*} \mathrm{~L}-\quad(\mathrm{L}+) \mathrm{H}^{*} \quad \mathrm{~L}-\mathrm{L} \%$

rendition 2: $\quad(\mathrm{L}+) \mathrm{H}^{*} \mathrm{~L}-\mathrm{L} \%(\mathrm{~L}+) \mathrm{H}^{*} \quad \mathrm{~L}-\mathrm{L} \%$ 
Table 1 (continued)
(h) UNACC.-UNACC.
Prompt: Did you say "Big Bah bopped the boy last night"?
Target: No, " Little Bah \# bopped the girl"
rendition 1: $\quad(\mathrm{L}+) \mathrm{H}^{*} \mathrm{~L}-\quad(\mathrm{L}+) \mathrm{H}^{*} \mathrm{~L}-\mathrm{L} \%$
rendition 2: $\quad(\mathrm{L}+) \mathrm{H}^{*} \quad \mathrm{~L}-\mathrm{L} \% \quad(\mathrm{~L}+) \mathrm{H}^{*} \mathrm{~L}-\mathrm{L} \%$

\begin{abstract}
Note that L\% refers to the IP boundary which is marked by a low (L) boundary tone; L- refers to a phrasal (low) tone that marks the end of the intermediate phrase; $\mathrm{L}$ - before a boundary tone $(\mathrm{L} \%)$ means that the intonational pattern is maintained low before the boundary tone; and $\mathrm{H}^{*}$ refers to a nuclear-pitch accent marked by a high $(\mathrm{H})$ pitch on an accented word.
\end{abstract}

\title{
2.2. Procedures
}

The target sequences were obtained from real sentences in a mini discourse situation intended to induce the desired variety of accent-placement patterns and prosodic groupings. A sample sentence set is given in Table 1. (See Appendix A for the remaining sentence sets.) In each target sentence, the words highlighted in bold receive pitch accent. The prompt was then read silently by the speaker to help cue the intended renditions, which were also provided using partial ToBI transcriptions in the script (see Section 2.3 for more information about ToBI transcriptions). The speakers were asked to produce sentences at their comfortable rate of speech. In order to have a balanced number of tokens for ip and IP, for each sentence listed in the second half ((e)-(h)) of Table 1, speakers were asked to produce two different renditions: one with ip (rendition 1) and one with IP (rendition 2). (Given the practice session, speakers were competent in producing both the ip and IP versions for each sentence.)

Thus, each speaker produced 48 different types of sentence tokens ( 3 prosodic boundaries $(\mathrm{Wd}$, ip, IP) $\times 2$ preboundary accentual patterns $($ acc vs. unacc) $\times 2$ postboundary accentual patterns $($ acc vs. unacc $) \times 4$ vowel pairs $(/ \mathrm{a} \# \mathrm{a} /, / \mathrm{i} \# \mathrm{i} /, / \mathrm{a} \# \mathrm{i} /$, , and $/ \mathrm{i} \# \mathrm{a} /))$. Each sentence was read twice in succession, and the entire list was read twice, for a total of four repetitions per sentence. This yielded a total of 1152 sentence tokens for analysis (48 sentence types $\times 6$ speakers $\times 4$ repetitions).

An EMA system (Carstens Articulograph AG 100) was used to track articulatory movements of the articulators. (See Schoenle, 1988; Schoenle, Mueller, \& Wenig, 1989; Tuller, Shao, \& Kelso, 1990; Hoole, 1996; Cho, 2002 for more technical information on the Carstens system; cf. Perkell et al., 1992.)

Eight transducer coils were used in the experiment. Reference transducers were placed on the nose and upper gumline, or maxilla, in order to correct for head movement inside the helmet. The remaining six transducers were located on articulators, but for the purpose of the coarticulatory study, only the tongue dorsum and midtransducers were considered for analysis. These transducers were placed on the tongue midsagittally: one at the tongue dorsum and one at the tongue mid-section, about 5 and $2.5 \mathrm{~cm}$ from the tongue tip, respectively. 
Next, in order to align the articulatory space to the occlusal plane (based on a line from the lower edge of the upper central incisors to the lower edge of the upper molars), a bite-plate with two additional transducers was used (see Westbury, 1994 for a further discussion of the efficacy of the occlusal plane). The articulatory space was rotated so that the $x$-axis was the occlusal plane. This rotation provided the corrected horizontal $(x)$ axis in the coordinate system, so that the $x$ axis was parallel to the bite (i.e., occlusal) plane with the $y$-axis being perpendicular to that. This was consistent across speakers. The EMA data were sampled at $500 \mathrm{~Hz}$. Acoustic recordings were made for lining up the kinematic signals with the acoustic signals and for the detection of acoustic landmarks such as beginnings and ends of vowels. The obtained kinematic signals were then submitted to low-pass filtering with a filter cutoff of $50 \mathrm{~Hz}$. (For detailed procedures, see the UCLA Phonetic Lab website (www.humnet.ucla.edu/humnet/linguistics/faciliti/facilities/physiology/ema.html).)

\subsection{Prosodic transcription}

The relevant $\mathrm{C}_{1} \mathrm{~V}_{1} \# \mathrm{C}_{2} \mathrm{~V}_{2}$ portion of the audio recording was transcribed with the aid of an acoustic display by two trained ToBI transcribers (one the author) following the criteria set forth in the ToBI transcription system (Silverman et al., 1992; Beckman \& Elam, 1997). In general, pitch accents received either $\mathrm{H}^{*}$ or $\mathrm{L}+\mathrm{H}^{*}$, and three prosodic boundaries were identified: the IP boundary (marked by a boundary tone and a break index 4); the ip boundary (marked by a break index 3, a phrasal tone and no boundary tone); the $\mathrm{Wd}$ (marked by a break index 1, in the middle of an ip). The phrase tone was always $\mathrm{L}^{-}$, and the boundary tone was either $\mathrm{L} \%$ or $\mathrm{H} \%$. Fig. 2 shows sample tokens of $/ \mathrm{ba} \# \mathrm{ba} /$ with ACC-UNACC sequences for three prosodic boundaries.

The two transcribers identified the same pitch accent locations in every token of the entire data set. The only difference between the transcribers came from their choice between the IP boundary and the ip boundary. Because the difference between IP and ip boundaries is an important experimental variable in this study, only tokens whose renditions were agreed on by the two transcribers were used for analysis. Out of 1152 sentence tokens, the transcribers reached agreement on transcriptions of 1109 tokens $(96.3 \%)$.

\subsection{Measurements}

Positional values for $x$ and $y$ for the tongue mid and tongue dorsum were measured at a variety of acoustic timepoints: the third quarter $\left(\frac{3}{4} V_{1}\right)$ and end of $V_{1}$; the first quarter $\left(\frac{1}{4} B\right)$, and third quarter $\left(\frac{3}{4} B\right)$ of the intervening $/ b /$; the onset and first quarter $\left(\frac{1}{4} V_{2}\right)$ of $V_{2}$.

It was necessary to normalize speaker differences, specifically for the size of their vocal tracts and tongues, and the position of the EMA helmet. For example, tongue fronting by $10 \mathrm{~mm}$ should be interpreted as a larger effect for a speaker with a smaller front-back tongue movement space (say, $100 \mathrm{~mm}$ ) than for a speaker with a larger front-back tongue movement space (say, $300 \mathrm{~mm}$ ). Thus, to get compatible data across speakers, the minimum and maximum of $x$ and $y$ values were obtained for each speaker, such that, for a given speaker, the minimum $x$ value was the extreme case of $/ \mathrm{i} /$ (the most fronted tongue position for $/ \mathrm{i} /$ ) and the maximum $x$ value was the extreme case of $/ \mathrm{a} /$ (the most retracted tongue position for $/ \mathrm{a} /$ ). Likewise, the minimum $y$ value was the extreme case of $/ \mathrm{a} /$ (the lowest tongue position for $/ \mathrm{a} /$ ) and the maximum $y$ value was the extreme 
(a) \#= the Word boundary (Wd)

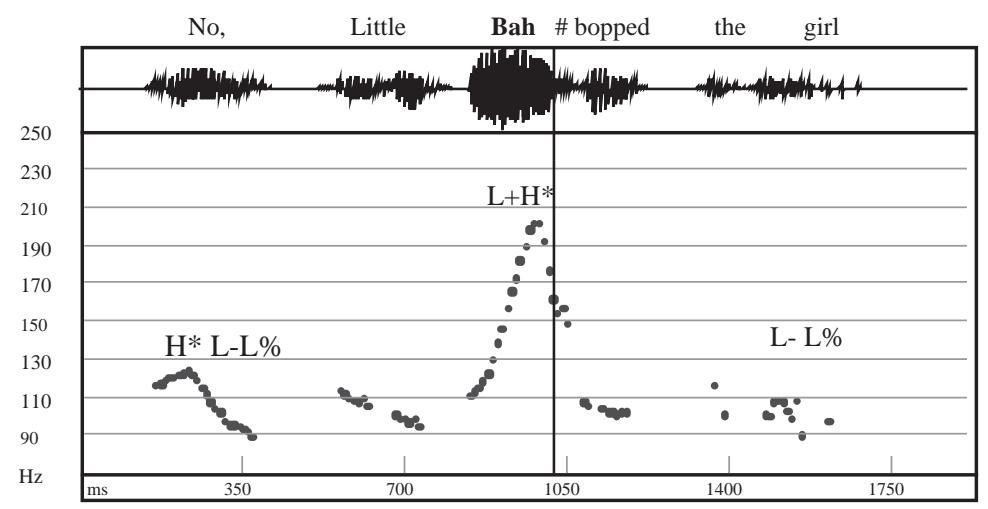

(b) \#=the Intermediate Phrase boundary (ip)

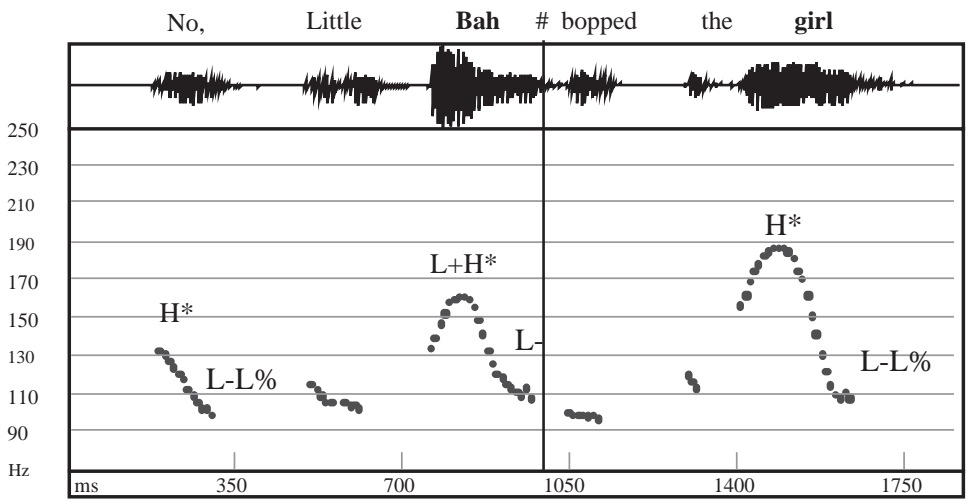

(c) \#= the Intonational Phrase boundary (IP)

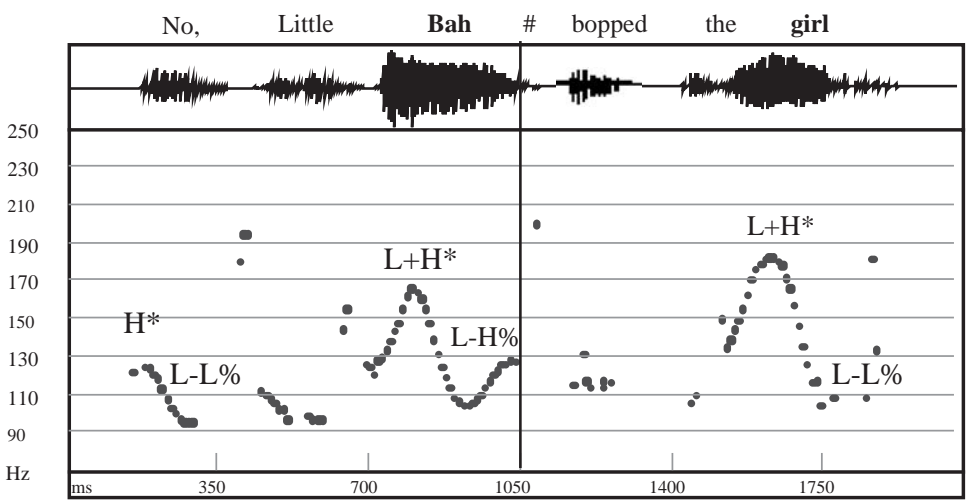

Fig. 2. Samples of ToBI transcriptions for /ba\#ba/, ACC-UNACC with varying prosodic boundaries: (a) the word boundary (marked by neither a phrasal tone nor a boundary tone and the break index of 1), (b) the intermediate phrase boundary (marked by a phrasal tone ( $\mathrm{L}-$ ) and the break index of 3 ), and (c) the intonational phrase boundary (marked by a boundary tone $(\mathrm{H} \%)$ and the break index of 4$)$. Note also that $\mathrm{L}+\mathrm{H}^{*}$ indicates the pitch pattern associated with nuclear-pitch accent. The vertical line indicates the acoustic endpoint of the preboundary vowel. 
case of $/ \mathrm{i} /$ (the highest tongue position for $/ \mathrm{i} /$ ). Absolute $x$ and $y$ values were then converted to percentage-point values relative to the minimum and maximum $x$ and $y$ values. For example, if a speaker had a minimum $x$ value of $100 \mathrm{~mm}$ and a maximum $x$ value of $300 \mathrm{~mm}$, then an $x$ value of $200 \mathrm{~mm}$ was normalized as $50 \%$. Thus, an obtained percentage value 50 for any given speaker indicates that the tongue is positioned half way between the two extremes regardless of whether the speaker's movement space is larger or smaller. ${ }^{3}$

In this experiment, the main interest lies in $\mathrm{V}$-to-V coarticulatory patterns observed in the overall tongue body configuration, rather than a single point on the tongue. Thus, normalized values were averaged over the tongue mid and the tongue dorsum, and the analysis and discussion will be based on this averaged data. ${ }^{4}$

Two kinds of comparisons were made in assessing the degree of coarticulation. The first examined paradigmatic coarticulatory effects, by comparing spatial values (in the $x$ and $y$ dimensions) for the test vowels $\left(\mathrm{V}_{1} \neq \mathrm{V}_{2}\right)$ with those for the control vowels $\left(\mathrm{V}_{1}=\mathrm{V}_{2}\right)$, as prosodic boundary and accentuation varies. Note that accentuation in the target (encroached) vowel will be referred to simply as accent and the accentuation in the (encroaching) vowel across a boundary, as neighboring accent.

The terms $X$ - and $Y$-distance are used to indicate the distance between the test and control vowels in $x$ (the tongue backness) and $y$ (the tongue height) dimensions, as illustrated in Fig. $3 \mathrm{a}$. The greater the distance, the greater the coarticulatory effect, because the test vowel has been pulled away more from the control vowel and pushed towards the encroaching vowel.

The second type of measurement was of the spatial difference between the positional values of the two consecutive opposite vowels (e.g., /a\#i/). This was used to assess the overall degree of syntagmatic coarticulation regardless of its directionality (the reciprocal coarticulatory effect). In this case there is no comparison between control and test vowels. The two data points were extracted from two different timepoints of a single sentence token: one was a preboundary point (e.g., $\mathrm{V}_{1}$ end), and the other was a postboundary point (e.g., $\mathrm{V}_{2}$ onset), as illustrated in Fig. 3 b. $X$ - and $Y$-distances between the two data points were calculated for three intervals to examine coarticulatory patterns not only at vowel edges but also further into the vowels and the intervening consonant: (1) $\frac{3}{4} V_{1}-\frac{1}{4} V_{2}$, (2) $V_{1}$ end $-V_{2}$ onset, and (3) $\frac{1}{4} B-\frac{3}{4} B$. These measurements do not tell how much the observed degree of coarticulation was due to a carryover effect vs. an anticipatory effect, but rather they indicate the overall degree of coarticulation, combining the two directional effects. These measures will be referred to as cross-boundary distances. In this case, a larger distance indicates a lesser degree of coarticulation, in that the consecutive vowels are more differentiated.

\footnotetext{
${ }^{3}$ Stevens' $(1972,1989)$ quantal theory suggests that a small amount of tongue movement in a critical area of the vocal tract may yield a greater acoustic consequence than a large amount of tongue movement in a less critical area. Further, it has been reported that high variability is observed for movements of articulators that are not critical in the formation of constriction (Papcun, Hochberg, Thomas, Laroche, Zacks, \& Levy, 1992). While this possibility requires caution in interpreting any production data, it is beyond the scope of this study to investigate the relationship between articulatory movements and their direct acoustic consequences.

${ }^{4}$ The $x$ and $y$ values for the tongue mid and tongue dorsum transducers were highly correlated, as suggested by $R$ values (ranging from 0.74 to $0.915, p<0.001$ ): For $x$ values, $\frac{3}{4} \mathrm{~V}_{1}, R=0.74 ; \mathrm{V}_{1}$ end, $R=0.745 ; \mathrm{V}_{2}$ onset, $R=0.831$; $\frac{1}{4} \mathrm{~V}_{2}, R=0.847$; for $y$ values, $\frac{3}{4} \mathrm{~V}_{1}, R=0.754 ; \mathrm{V}_{1}$ end, $R=0.824 ; \mathrm{V}_{2}$ onset, $R=0.914 ; \frac{1}{4} \mathrm{~V}_{2}, R=0.915$.
} 
(a) Distances between test and control vowels

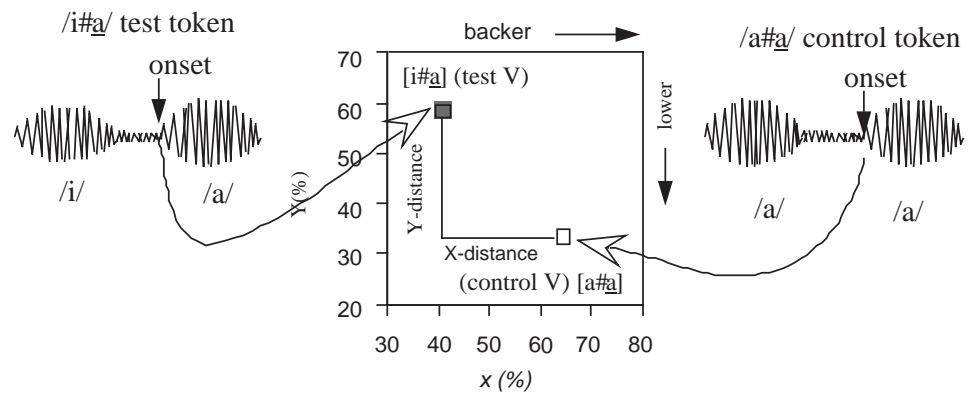

(b) Cross-boundary distance beween opposite vowels

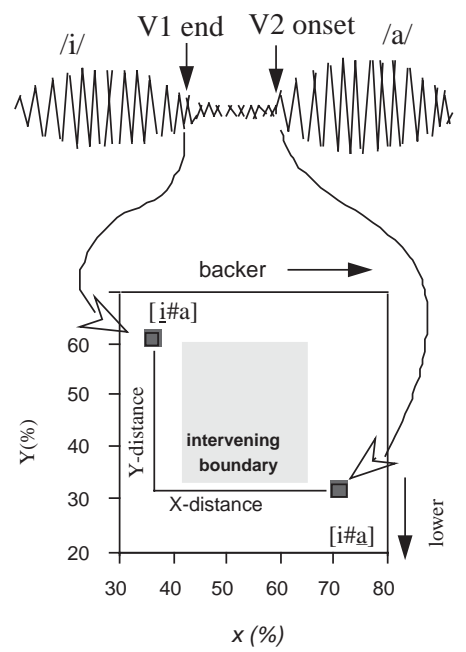

Fig. 3. (a) $X$-, and $Y$-distances between test and control vowels; the shorter the distance, the less coarticulation. (b) Cross-boundary distances between consecutive vowels spanning a prosodic boundary; the shorter the distance, the more coarticulation.

Finally, V-to-V temporal (durational) differences were measured for the same three intervals used to examine the reciprocal coarticulatory effect. This was done to explore the relationship between reciprocal coarticulation and duration. The interval between $\mathrm{V}_{1}$ end and $\mathrm{V}_{2}$ onset was measured as the acoustic duration of the intervening $/ \mathrm{b} /$ plus a potential pause.

To report the results, target (encroached) vowels are underlined as in $/ \mathbf{i} \# \mathrm{a} /$ or $/ \mathrm{i} \# \mathrm{a} /$ - e.g., $/ \mathrm{i} \# \mathrm{a} /$ means that the target is /i/ and coarticulation is examined in the anticipatory direction; similarly, /i\#a/ means that the target vowel is /a/ in the carryover direction.

\subsection{Statistics}

Evaluation of the systematic influence of prosodic factors was primarily based on repeated measures analyses of variance (ANOVAs). The individual subjects were the experimental units. In other words, each data point was an averaged value over three or four repetitions of each prosodic and vowel context. (For a small number of data points (43 out of 288 data points submitted 
to ANOVAs), only three repetitions were available because the tokens with inter-transcriber disagreement on IP vs. ip were excluded. In this case, data points were averaged values over three repetitions.) There were no between-subjects experimental factors. The within-subject factors considered for the analysis of carryover and anticipatory effects were boundary (IP, ip, Wd), accent (ACC, UNACC), and neighboring accent (ACC, UNACC). The results for the analysis of the carryover and anticipatory effects are based on repeated measures three-way ANOVAs performed separately for $/ \mathrm{a} /$ and $/ \mathrm{i} /$. In order to avoid violating the sphericity assumption, HuynhFeldt corrected degrees of freedom were used in generating $F$ ratio and $p$ values (Huynh \& Feldt, 1970). As a result, degrees of freedom and error terms in integer were often reduced to fractional values, as reported in the present study (e.g., $F[2,10] \rightarrow F[1.6,9.6]$ ). (See Max \& Onghena, 1999 for a tutorial on various statistical issues.) Less than $0.05 p$-values are considered significant.

In order to observe patterns within a factor, posthoc tests were performed when there is a significant effect. A Bonferroni correction was employed using the Bonferroni/Dunn model, to compensate for potential heterogeneous variances and correlations among the observations, especially in cases of repeated observations and of multiple pair-wise comparisons. As a safeguard, a conservative criterion for confidence level was used with the alpha level of $3 \%$ (equivalent to $p<0.01$ when there are three levels to compare in a factor).

For the analysis of reciprocal coarticulatory effects, data were submitted to repeated measures four-way ANOVAs with vowel sequence $(/ \mathrm{a} \# \mathrm{i} / \mathrm{vs}$. $/ \mathrm{i} \mathrm{Ha} /)$ as an additional within-subject factor. This procedure was done separately for each timepoint tested. Finally, to examine whether the variation in duration affects the degree of coarticulation, the analysis of covariance (ANCOVA) was employed with the duration factor as a covariate (regressor).

\section{Results}

\subsection{Carryover effect (domain-initial target vowels)}

In this section, carryover coarticulatory effects are examined-i.e., how much a domain-initial target vowel is coarticulated with the preceding vowel as a function of prosodic factors (accent, neighboring accent, prosodic boundary). In what follows, the effect of each factor will be reported first, followed by the interactions between factors, and finally with a summary of main effects. $F$-values and significance levels are given in Appendix B.

\subsubsection{Effect of accent}

There are main effects of accent on carryover coarticulation on $Y$-distance (the tongue height dimension), regardless of vowel type. As shown in the right panels of Fig. 4, $Y$-distance is significantly shorter when the target vowel is accented (as indicated by the white bars) than when it is unaccented (for $/ \# \mathrm{~A} /$ at $\frac{3}{4} \mathrm{~B}$ and at the $\mathrm{V}_{2}$ onset and for $/ \# \mathrm{H} /$ at $\frac{1}{4} \mathrm{~V}_{2}$ ). (Recall that shorter $X$ - and $Y$-distances indicate less coarticulation.) However, as shown in the left panels of Fig. 4, no significant main effect is found for either vowel type at any of the timepoints on the tongue backness $(x)$ dimension, though there are some cases with trends. These results show that accented vowels are coarticulated less with preceding vowels than unaccented vowels are, at least along the tongue height $(y)$ dimension. 
(a) Domain-initial /\#a/
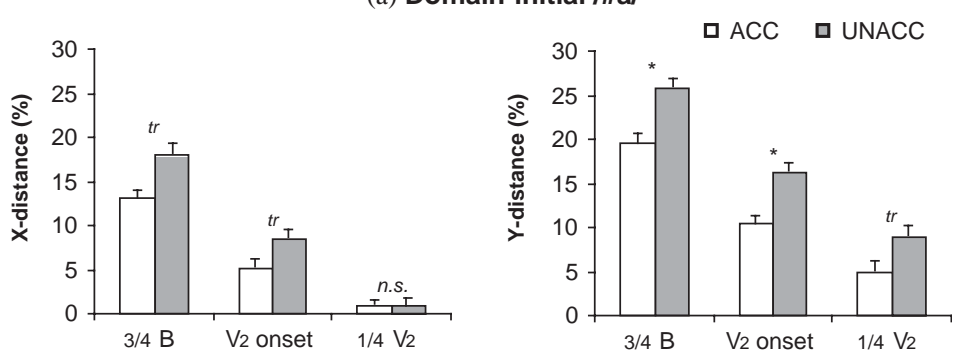

(b) Domain-initial /\#i/
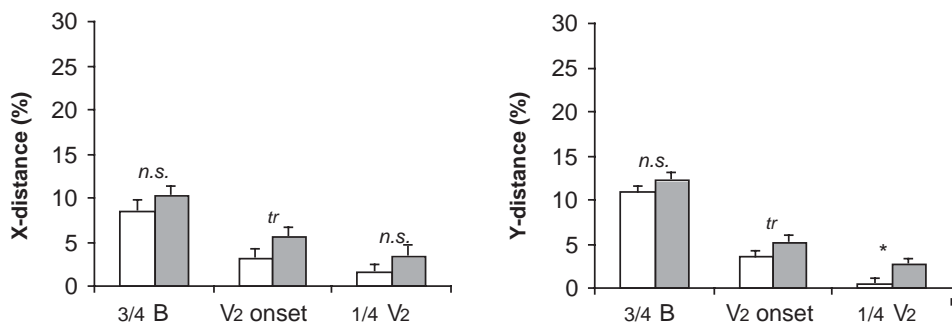

Fig. 4. The effect of accent on carry-over coarticulation: (a) /i\#/ / and (b) /a\#i/. White bars mean that the postboundary target vowels are accented. Mean values of $X$ - and $Y$-distances are plotted separated for each time point. $\left({ }^{*} p<0.05 ;{ }^{\text {tr }} 0.05<p<0.07\right.$; n.s., $p>0.07$ from repeated measures ANOVAs; see Table 2 for $F$-values.)

\subsubsection{Effect of boundary}

There is a significant main effect of prosodic boundary on /\#a/ for both $X$ - and $Y$-distances at two timepoints $\left(\frac{3}{4} \mathrm{~B}\right.$, and $\mathrm{V}_{2}$ onset). As shown in Fig. 5a, there are significantly smaller $X$ - and $Y$-distances after higher boundaries as compared to lower boundaries. There is a two-way distinction (IP $<(\mathrm{ip}=\mathrm{Wd}), p<0.01)$ in both $X$ - and $Y$-distances for all three timepoints, except for $X$-distance at $\frac{3}{4} \mathrm{~B}$, which has a three-way distinction (IP $<\mathrm{ip}<\mathrm{Wd}, p<0.01$ ). This shows that the prosodic boundary influences both $X$ - and $Y$-distances such that $/ \# \mathrm{a} /$ is coarticulated less with the preceding vowel /i\#/ after a higher than lower boundary in both $x$ and $y$ dimensions.

Turning to $/ \mathrm{Hi} /$, there is a significant effect of boundary, but only for $Y$-distance (at two timepoints: at $\frac{3}{4} \mathrm{~B}$ and $\mathrm{V}_{2}$ onset), as shown in Fig. 5b. $Y$-distance is significantly smaller for the IP boundary than for lower boundaries $(\mathrm{IP}<(\mathrm{ip}=\mathrm{Wd}), p<0.01)$, showing boundary-induced coarticulatory reduction in the tongue height $(y)$ dimension.

Overall, the results reveal that postboundary (domain-initial) vowels are coarticulated less with preceding vowels across a higher prosodic boundary (IP) than across a lower prosodic boundary (ip, Wd). For $/ \# \mathrm{a} /$, this is true for both the tongue height $(y)$ and backness $(x)$ dimensions, but for /\#i/ only in the tongue height $(y)$ dimension.

\subsubsection{Accent effect of the neighboring vowel}

There is no significant main effect of neighboring accent on any of the dependent variables; therefore, there is no support for the coarticulatory aggression hypothesis which hypothesized that an accented vowel encroaches on a target vowel more than an unaccented vowel does. 
(a) Domain-initial /\#a/
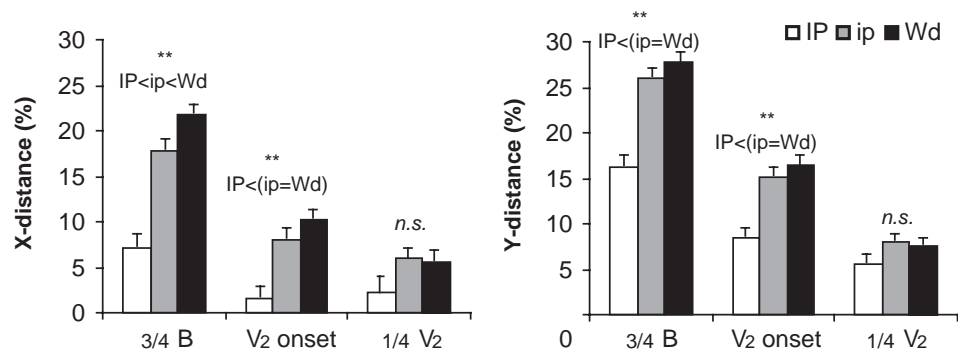

(b) Domain-initial /\#i/
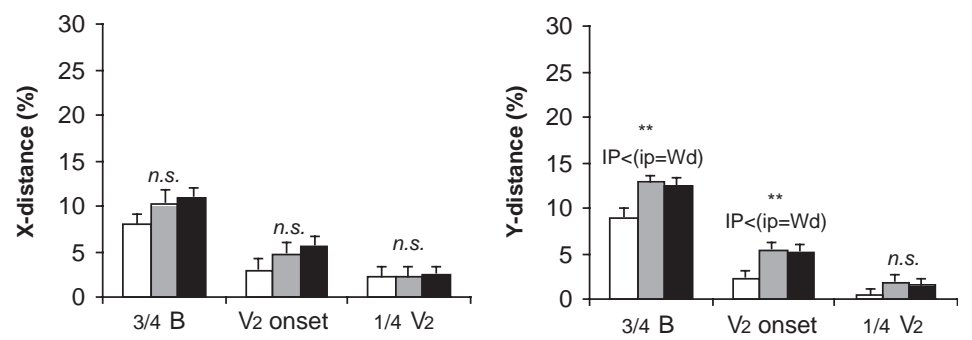

Fig. 5. The effect of boundary on carry-over coarticulation: (a) /i\#a/ and (b) /a\#隹. Mean values of $X$ - and $Y$-distances are plotted separated for each time point. $\left({ }^{* *} p<0.01 ;{ }^{*} p<0.05 ;{ }^{\text {tr }} 0.05<p<0.07\right.$; n.s., $p>0.07$ from repeated measures ANOVAs; " $<$ " refers to $p<0.01$ obtained by Bonferroni/Dunn posthoc comparisons; see Table 2 for $F$-values.)

\subsubsection{Interactions}

There are no interactions between prosodic factors in the carryover effect on either vowel type. In particular, the lack of interaction between accent and neighboring accent confirms that accent on the neighboring vowel does not influence the articulation of the target vowel, whether the target vowel is accented or not.

\subsubsection{Summary of carryover effects}

First, accented vowels are coarticulated less with preceding vowels than unaccented vowels are, primarily in the tongue height $(y)$ dimension, and postboundary vowels are coarticulated less with preceding vowels across higher prosodic boundaries than across lower prosodic ones. This supports the coarticulatory reduction hypotheses with respect to both accent and boundary factors. Second, neither a main effect of the accent of the neighboring vowel nor a significant interaction between factors was found, suggesting that the accentuation of a neighboring vowel does not influence how much the target vowel is coarticulated with it, weakening the coarticulatory aggression hypothesis.

\subsection{Anticipatory effect (domain-final target vowels)}

This section reports results with respect to how much the articulation of a preboundary (domain-final) vowel is influenced by a different postboundary vowel. 
(a) Domain-final /a\#/
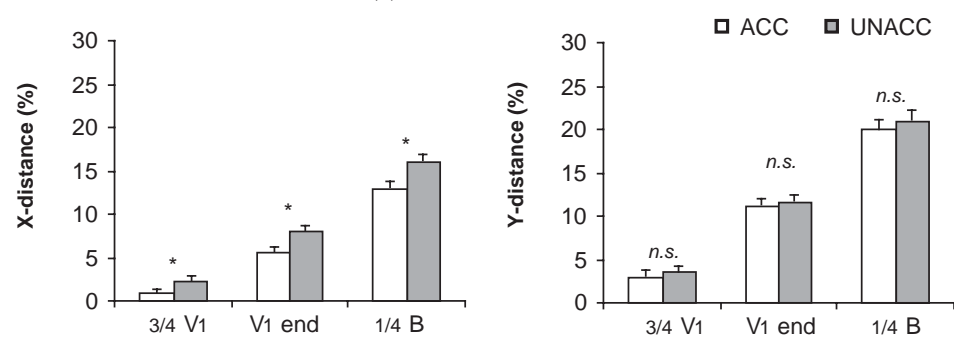

(b) Domain-final /i\#/
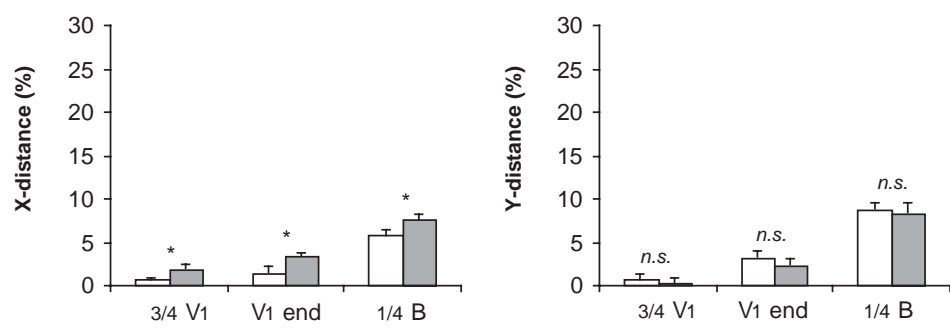

Fig. 6. The effect of accent on anticipatory coarticulation: (a) /a $\#$ i/ and (b) /i $\# \mathrm{a} /$. Mean values of $X$ - and $Y$-distances are plotted separated for each time point. $\left({ }^{*} p<0.05 ;{ }^{\mathrm{tr}} 0.05<p<0.07\right.$; n.s., $p>0.07$ from repeated measures ANOVAs; see Table 3 for $F$-values.)

\subsubsection{Effect of accent}

There is a significant main effect of accent on $X$-distance (the tongue backness $(x)$ dimension) at all timepoints for both $/ \mathrm{a} \# /$ and $/ \mathrm{i} \# /$, while there is no main effect of accent on $Y$-distance (the tongue height $(y)$ dimension), as shown in Fig. 6. The $X$-distance is significantly shorter for accented vowels than for unaccented ones, showing accent-induced coarticulatory reduction primarily in the tongue backness $(x)$ dimension.

\subsubsection{Effect of boundary}

$X$-distance shows a significant main effect on preboundary /a\#/ at $\frac{3}{4} \mathrm{~V}_{1}$, and $Y$-distance at the end of $\mathrm{V}_{1}$ and $\frac{1}{4} \mathrm{~B}$ (Fig. 7a): $X$ - and $Y$-distances are significantly shorter before a higher prosodic boundary than before a lower prosodic boundary. In posthoc comparisons, a three-way distinction (IP $<\mathrm{ip}<\mathrm{Wd}, p<0.01)$ is made at $\frac{3}{4} \mathrm{~V}_{1}$ for $X$-distance and a two-way distinction (IP $<(\mathrm{ip}=\mathrm{Wd}), p<0.01)$, at the end of $\mathrm{V}_{1}$ and $\frac{1}{4} \mathrm{~B}$ for $Y$-distance. This shows that the coarticulatory reduction of $/ \mathrm{a} \# /$ to a following $/ \mathrm{Hi} /$ is greater across higher prosodic boundaries than across lower ones in both tongue backness $(x)$ and height $(y)$ dimensions. In contrast to /a\#/, /i\#/ does not show any effect of boundary, as seen in Fig. $7 \mathrm{~b}$.

\subsubsection{Accent effect of the neighboring vowel}

There is no significant effect of neighboring accent on any of the dependent variables at any timepoint. In other words, accented vowels do not induce stronger coarticulatory effects on neighboring vowels than unaccented vowels do; thus, no support is found for the coarticulatory aggression hypothesis. 
(a) Domain-final /a\#/
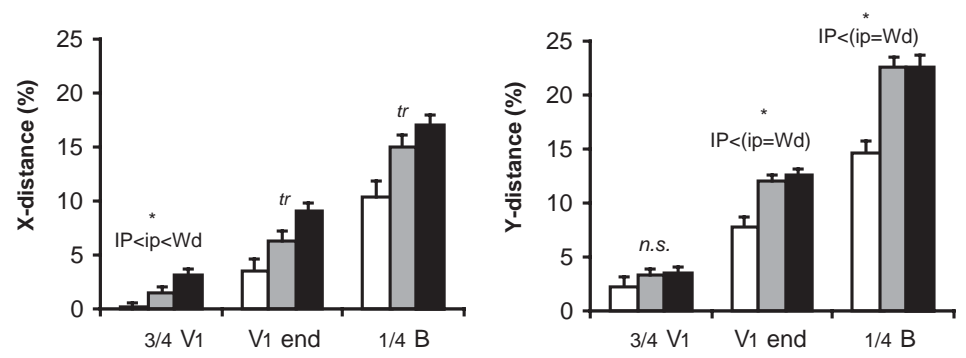

(b) Domain-final /i\#/
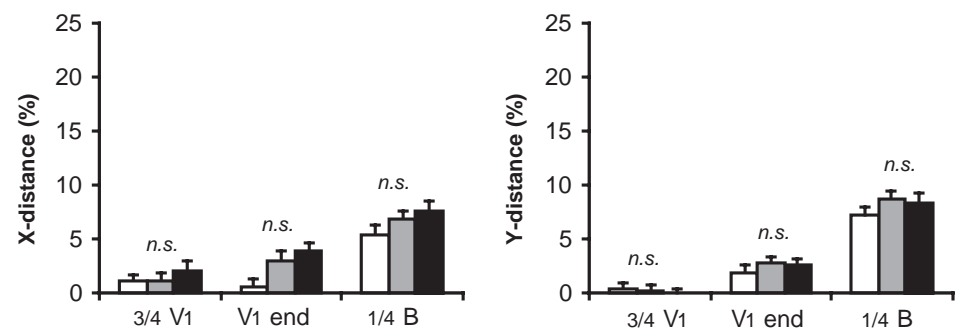

Fig. 7. The effect of boundary on anticipatory coarticulation: (a) $/ \mathbf{a} \# \mathrm{i} /$ and (b) $/ \mathbf{i} \# \mathrm{a} /$. Mean values of $X$ - and $Y$ distances are plotted separated for each time point. $\left({ }^{*} p<0.05\right.$; ${ }^{\mathrm{tr}} 0.05<p<0.07$; n.s., $p>0.07$ from repeated measures ANOVAs; " $<$ " refers to $p<0.01$ obtained by Bonferroni/Dunn posthoc comparisons; see Table 3 for $F$-values.)

\subsubsection{Interactions}

For $/ \mathrm{a} \# /$, there are no interactions between factors, whereas for $/ \mathrm{i} \# /$, a three-way accent $\times$ boundary $\times$ neighboring accent interaction is found at three timepoints $\left(\frac{3}{4} \mathrm{~V}_{1}, \mathrm{~V}_{1}\right.$ onset, and $\left.\frac{1}{4} \mathrm{~B}\right)$ for $X$-distance $(F[1.8,8.9]=8.640, p<0.005$ and $F[2,10]=23.418, p<0.001, F[1.9,9.5]=7.272$, $p<0.025$, respectively). One point to be drawn from this interaction is that there is a clear three-way distinction (IP $<\mathrm{ip}<\mathrm{Wd}, p<0.01)$ between prosodic levels when the target vowel $/ \mathrm{i} \# /$ is accented and followed by an unaccented vowel /\#a/. This shows that boundary effects are conditioned by the accentuation of vowels, such that the accented target vowel $(/ \mathrm{i} \# /)$ is more sensitive to the boundary type when the neighboring vowel is unaccented than accented.

\subsubsection{Summary of anticipatory effects}

First, accented domain-final target vowels are coarticulated less with following encroaching vowels than unaccented target vowels are, supporting the accent-induced coarticulatory reduction hypothesis. Second, there is a main effect of Boundary on $/ \mathrm{a} \# \mathrm{i} /$, but not on $/ \mathrm{i} \# \mathrm{a} /$, showing that preboundary $/ \mathrm{a} \# /($ not $/ \mathrm{i} \# /)$ is coarticulated less with the following vowel $/ \mathrm{i} /$ across higher than lower prosodic boundaries. Finally, there was no main effect of the accent of a neighboring (postboundary) vowel and no significant interaction between accent factors of the target and the neighboring vowel; therefore, no support was found for the coarticulatory aggression hypothesis. 


\subsection{The reciprocal coarticulatory effect}

This section reports results on reciprocal effects, which are used to assess the overall degree of coarticulation, regardless of its directionality (syntagmatic assessment). Recall that the dependent variables are cross-boundary $X$ - and $Y$-distances between opposite vowels for three time intervals: (1) $\frac{3}{4} V_{1}-\frac{1}{4} V_{2}$, (2) $V_{1}$ end $-V_{2}$ onset, and (3) $\frac{1}{4} B-\frac{3}{4} B$. These distances will show how close the articulations are of two consecutive but different vowels. A shorter cross-boundary distance means a greater degree of syntagmatic coarticulation, meaning that the consecutive vowels are closer to each other, as opposed to the cases of carryover and anticipatory coarticulatory effects reported above, where a shorter distance between the test and control conditions indicates a lesser degree of paradigmatic coarticulation.

\subsubsection{Effect of accent}

First consider the effect of preboundary $\left(\mathrm{V}_{1}\right)$ accent (Fig. 8a). There is no robust effect of preboundary accent on cross-boundary distances. A significant effect is obtained only for the time interval $\frac{1}{4} \mathrm{~B}-\frac{3}{4} \mathrm{~B}$ in $Y$-distance (tongue height) (the right panel of Fig. 8a). An unexpected pattern is found where the cross-boundary $Y$-distance is significantly shorter (indicating more coarticulation) when preboundary vowels $\left(\mathrm{V}_{1}\right)$ are accented than when they are unaccented. Given that this effect is found only for the interval during the consonant $\left(\frac{1}{4} \mathrm{~B}-\frac{3}{4} \mathrm{~B}\right)$ in $Y$-distance, it can be inferred that the accent of the preboundary vowel $\left(V_{1}\right)$ does not affect reciprocal coarticulation, at least not in the way that the accentuation of the preboundary vowel induces coarticulatory reduction, as was observed in the previous section. There is no significant interaction between accent and other factors.

In contrast to the case of the preboundary accent effect, postboundary accent does influence coarticulatory patterns (see Fig. 8b). For both cross-boundary $X$-, and $Y$-distances, there is a significant main effect of postboundary accent for all three intervals examined. The crossboundary distance is significantly greater (indicating a lesser degree of coarticulation) when postboundary vowels $\left(\mathrm{V}_{2}\right)$ are accented than when they are unaccented. This indicates that the accentuation of postboundary vowels triggers coarticulatory reduction, supporting the accentinduced coarticulatory reduction hypothesis.

However, there is a significant vowel sequence $(/ \mathrm{i} \# \mathrm{a} /$ vs. $/ \mathrm{a} \# \mathrm{i} /) \times$ postboundary accent interaction. Posthoc tests show that differences due to postboundary accent hold for /a\#i/ only for $X$-distance (only for $\frac{3}{4} \mathrm{~V}_{1}-\frac{1}{4} \mathrm{~V}_{2}$ ), and for $/ \mathrm{i} \# \mathrm{a} /$ only for $Y$-distance (for all three timepoints). In other words, the accent of $/ \mathrm{Hi} /$ induces cross-boundary coarticulatory reduction in the tongue backness $(x)$ dimension, and the accent of $/ \mathrm{Ha} /$ induces coarticulatory reduction in the tongue height $(y)$ dimension. (See Section 4.3 for further discussion.) There are no other significant interactions between factors.

\subsubsection{Effect of boundary}

As shown in Fig. 8c there is a significant effect of boundary on $Y$-distance in the $\mathrm{V}_{1}$ end- $\mathrm{V}_{2}$ onset interval, showing a greater cross-boundary $Y$-distance for a higher prosodic boundary. Posthoc pair-wise comparisons confirms a three-way distinction (IP $>\mathrm{ip}>\mathrm{Wd})(p<0.01)$, suggesting that on the $y$ dimension, vowels are coarticulated less with each other across higher prosodic 
(a) V1 ACC vs. UNACC $\quad$ aIP $\square$ ip $\square$ Wd
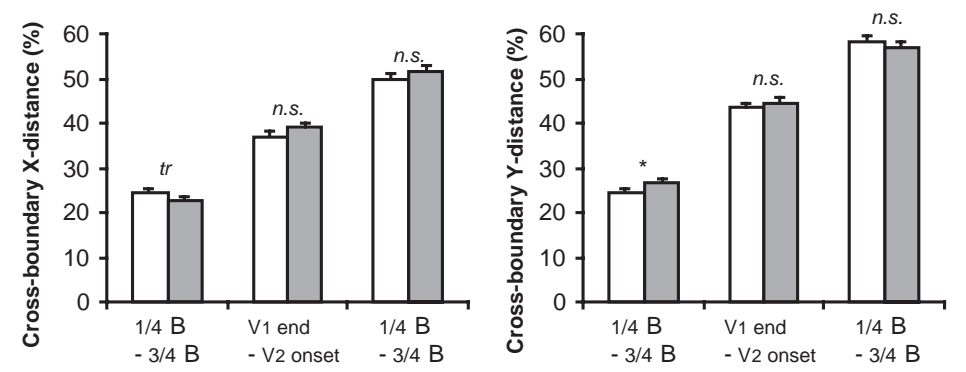

(b) V2 ACC vs. UNACC
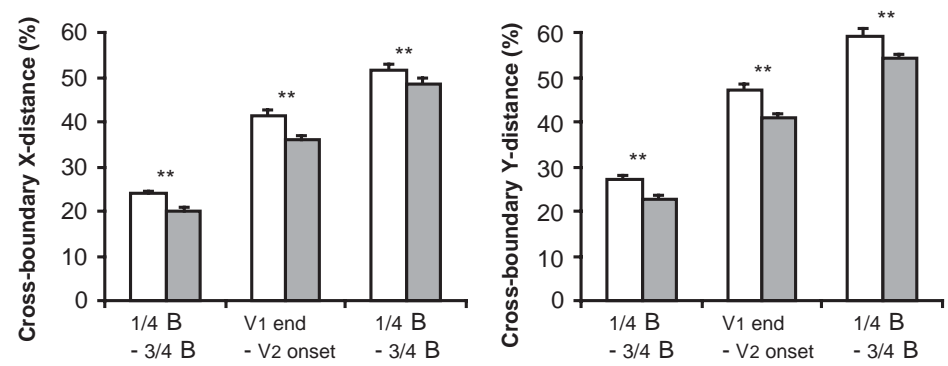

(c) Boundary: IP vs. ip vs. Wd
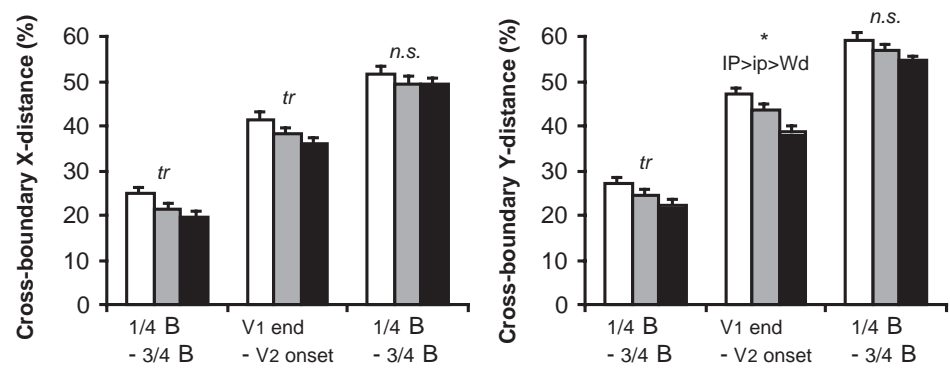

Fig. 8. Cross-boundary distances: (a) the effect of $\mathrm{V}_{1}$ accent, (b) the effect of $\mathrm{V}_{2}$ accent, and (c) the effect of boundary. Mean values of cross-boundary $X$ - and $Y$-distances are plotted separated for each time interval. $\left({ }^{* *} p<0.01 ;{ }^{*} p<0.05\right.$; ${ }^{\operatorname{tr}} 0.05<p<0.07$; n.s., $p>0.07$ from repeated measures ANOVAs; " $<$ " refers to $p<0.01$ obtained by Bonferroni/Dunn posthoc comparisons; see Table 2 for $F$-values.)

boundaries than across lower ones. In contrast, no significant effect is found for $X$-distance. This suggests that the boundary effect is primarily attributable to the articulatory patterns in the tongue height $(y)$ dimension.

\subsubsection{Summary of reciprocal coarticulatory effect}

The accentuation of a preboundary (domain-final) vowel $\left(\mathrm{V}_{1}\right)$ does not necessarily entail coarticulatory reduction, whereas the accentuation of a postboundary (domain-initial) vowel $\left(V_{2}\right)$ does have a significant influence on the reciprocal coarticulatory effect. Here the accentuation of $\mathrm{V}_{2}$ causes coarticulatory reduction mainly in the tongue height $(x)$ dimension for /a\#i/ 
and in the tongue backness $(y)$ dimension for $/ \mathrm{i \# a} /$. Second, the reciprocal coarticulatory pattern is significantly influenced by boundary mainly in the tongue height $(y)$ dimension-i.e., a greater coarticulatory reduction is found across higher prosodic boundaries than across lower ones.

\subsection{V-to-V temporal difference and coarticulatory resistance}

In the previous section, it was found that both boundary and accent significantly affect the degree of the reciprocal (syntagmatic) coarticulation (as measured by cross-boundary $X$-, and $Y$-distances). However, durational differences were not considered. It is possible though that coarticulatory reduction might be due to lengthening from boundary and/or accent or might be due to an increase in duration-independent coarticulatory resistance which is associated with prosodically stronger locations. This section first examines how the $\mathrm{V}$-to- $\mathrm{V}$ temporal difference between $V_{1}$ end and $V_{2}$ onset varies as a function of boundary and accent, and then examines whether and how much of the observed coarticulatory effects can be accounted for by a duration factor, V-to-V interval.

The results of repeated measures four-way ANOVAs showed that the $\mathrm{V}$-to- $\mathrm{V}$ interval (roughly equivalent to the duration of the intervening /b/ plus a potential pause that may be present immediately after an IP final vowel) is significantly affected by postboundary $\left(\mathrm{V}_{2}\right)$ accent $(F[1,5]=112.543, p<0.001)$ and boundary $(F[2,10]=4.882, p<0.05)$, but not by preboundary $\left(\mathrm{V}_{1}\right)$ accent. This result is compatible with the null effect found with preboundary $\left(\mathrm{V}_{1}\right)$ accent on cross-boundary articulatory measures, reported in the previous section. As can be seen in Fig. 9, the V-to-V interval is significantly longer when the postboundary vowel is accented. The interval is also longest for IP, intermediate for ip, and shortest for Wd, showing a significant three-way distinction $(p<0.005)$. There is no interaction between these two factors, suggesting that the difference due to postboundary accent is maintained across prosodic boundaries.

In order to examine whether the variation in duration affects the degree of coarticulation, the factorial model of the ANCOVA was employed with each cross-boundary distance $(X-$-, and $Y$-distances) for the time interval $\mathrm{V}_{1}$ end $-\mathrm{V}_{2}$ onset as a dependent variable, and duration as a

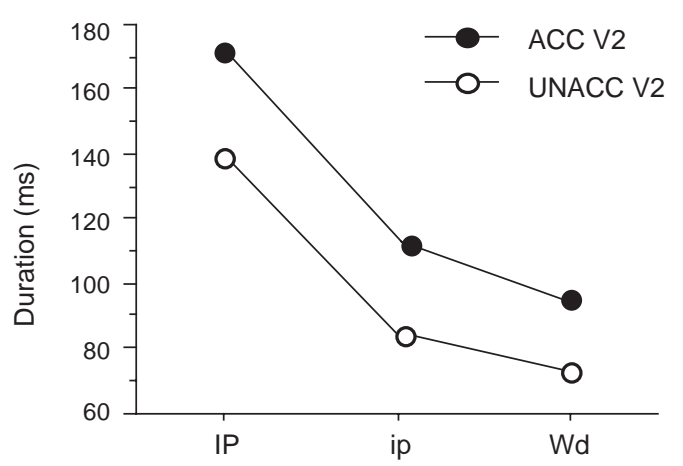

Fig. 9. Mean cross-boundary intervals (duration) between $V_{1}$ end and $V_{2}$ onset by postboundary $\left(\mathrm{V}_{2}\right)$ accent and boundary type. 
covariate (regressor) at that time interval. As Kirk (1995) noted, assumptions for the factorial model are less restrictive than with the repeated measures model, therefore, in conducting the factorial analysis, the level of significance was set to $p<0.01$. This counteracts the relatively large degrees of freedom which may inflate the size of the effect and possibly causing Type I error.

As a first step, to determine whether the regressor, duration, has a different effect on the degree of coarticulation for different levels of prosodic factors (i.e., postboundary $\left(\mathrm{V}_{2}\right)$ accent and boundary), a test for homogeneity of slopes among regression lines was conducted for each level of the factor. This test performs a separate regression for each condition of a factor and determines whether the relationship between the regressor (i.e., duration) and the factor (e.g., boundary) varies with the level of the factor. The results showed that there was no significant interaction between duration and either prosodic factor for any dependent variable, suggesting that the slope of the regressor did not differ statistically depending on the level of the factor. In other words, the hypothesis of homogeneity of slopes was supported. This then justifies an elimination of the interaction involving the covariate from the ANCOVA model (SAS 1990, pp. 80-81). Thus, ANCOVAs with no inclusion of covariate-factor interactions were performed for covariance of each dependent variable (cross-boundary $X$ - and $Y$-distances) and duration, with two factors postboundary $\left(\mathrm{V}_{2}\right)$ accent and boundary, separately for each vowel sequence $(/ \mathrm{a} \# \mathrm{i} /$ and $/ \mathrm{i} \# \mathrm{a} /)$.

Results of ANCOVAs show that for the $/ \mathrm{i} \# \mathrm{a} /$ sequence, duration of the time interval from $\mathrm{V}_{1}$ end to $\mathrm{V}_{2}$ onset significantly affects both dependent variables ( $X$ - and $Y$-distances) $(F[1,67]=15.605, p<0.0005$ for $X$-distance; $F[1,67]=29.697, p<0.0001$ for $Y$-distance $)$. This means that the degree of coarticulation co-varies significantly with the $\mathrm{V}$-to-V interval in the /i\#a/ sequence. However, for $/ \mathrm{a} \# \mathrm{i} /$, there is no significant effect of duration on either $X$ - or $Y$-distances $(F[1,67]=4.138, p=0.041 ; F[1,67]=3.219, p=0.054$, respectively $)$. These results show that the temporal duration affects the degree of coarticulation in $/ \mathrm{i} \# \mathrm{a} /$, but not reliably so in $/ \mathrm{a} \# \mathrm{i} /$. In other words, at least for the latter (the /a\#i/ sequence), prosodically conditioned variation in reciprocal (syntagmanic) coarticulation can be interpreted as a result of changes in duration-independent coarticulatory resistance.

As for the $/ \mathrm{i} \# \mathrm{a} /$ sequence, however, given that there is a significant covariance between duration and reciprocal coarticulatory distances, the next task is to determine whether there is still a significant effect of prosodic factors on coarticulation when the durational influence is factored out. With regards to the effect of postboundary $\left(\mathrm{V}_{2}\right)$ accent, results of ANCOVAs show that for $/ \mathrm{i} \# \mathrm{a} /$ there is a significant effect of accent on cross-boundary $Y$-distances, the tongue height $(y)$ dimension $(F[1,67]=25.686, p<0.0001)$, but not $X$-distances. (This is consistent with the reciprocal coarticulatory effect of postboundary $\left(\mathrm{V}_{2}\right)$ accent on $/ \mathrm{i} \mathrm{Ha} /$ which was found significant only in the tongue height $(y)$ dimension, as reported in the previous section.) In other words, even if the durational influence is factored in, there is still a reliable effect of accent-induced coarticulatory variation in the tongue height $(y)$ dimension in $/ \mathrm{i} \# \mathrm{a} /$. This suggests that the durational variation is not the only factor responsible for the accent-induced variation in the $/ \mathrm{iHa} /$ reciprocal coarticulation.

Turning to the boundary effect on $/ \mathrm{i} \mathrm{Aa} /$, when the durational influence is factored in, the effect of boundary is no longer significant, indicating that the boundary-induced coarticulatory patterning and durational effects for $/ \mathrm{i} \# \mathrm{a} /$ cannot be regarded as independent effects. In other 


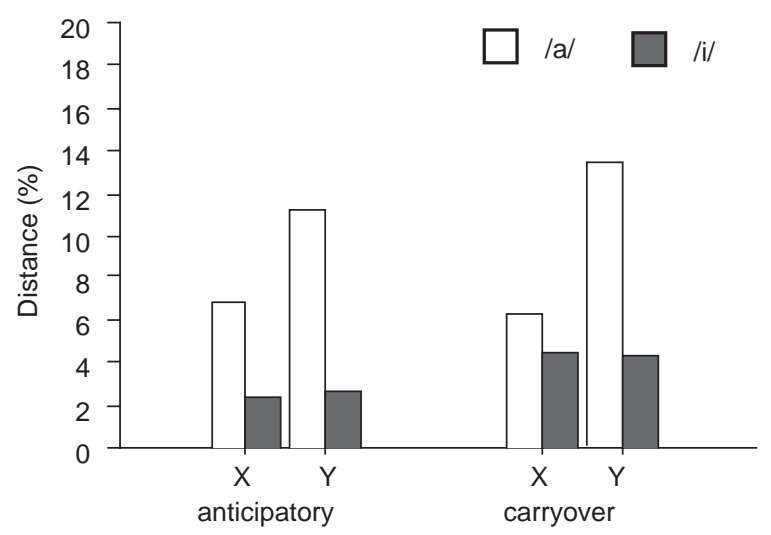

Fig. 10. Mean $X$ - and $Y$-distances between the test and control conditions for $/ \mathrm{a} /$ and $/ \mathrm{i} /$. The empty bar indicates how much /a/ coarticulates with its neighbor /i/ and the black bar indicates how much /i/ coarticulates with its neighbor /a/.

words, the boundary-induced coarticulatory variation cannot be attributed to changes in duration-independent coarticulatory resistance.

\subsubsection{Summary of the durational effects on coarticulation}

The results of the ANCOVA suggested that the accent effect on the reciprocal coarticulation cannot be accounted for by a duration factor alone for both $/ \mathrm{a} \# \mathrm{i} /$ and $/ \mathrm{i} \# \mathrm{a} /$ sequences, whereas the boundary effect may be attributable to the duration factor for $/ \mathrm{i} \# \mathrm{a} /$, but not for $/ \mathrm{a} \# \mathrm{i} /$.

\subsection{Inherent articulatory properties and coarticulation}

This section reports results regarding V-to-V coarticulatory variation as a function of the inherent segmental properties of $/ \mathrm{a} / \mathrm{vs}$. / i/. Results pooled across all prosodic conditions show that spatial distances between the test $\left(\mathrm{V}_{1} \neq \mathrm{V}_{2}\right)$ and control $\left(\mathrm{V}_{1}=\mathrm{V}_{2}\right)$ conditions are significantly greater for $/ \mathrm{a} /$ than for $/ \mathrm{i} /$ in both the carryover and anticipatory directions. Fig. 10 shows the mean difference across all prosodic conditions in $X$-, and $Y$-distances between $/ \mathrm{a} / \mathrm{and} / \mathrm{i} /$. The difference is significantly greater for $/ \mathrm{a} /$ than for $/ \mathrm{i} /$ for all cases $(p<0.0001)$. That is, the open vowel $/ \mathrm{a} /$ is more vulnerable to coarticulation than the closed vowel $/ \mathrm{i} /$ across a consonant $/ \mathrm{b} /$ independently of prosodic conditions. Therefore, a greater coarticulatory resistance is seen for $/ \mathrm{i} /$ than for $/ \mathrm{a} /$. This lends support to the hypothesis that coarticulatory resistance is inversely correlated with sonority (Lindblom, 1983). This hypothesis has primarily been tested with consonantal coarticulatory resistance. For example, it has been demonstrated that there is an inverse relationship between the degree of coarticulation and the amount of linguopalatal contact required for the articulation of lingual consonants (Recasens, 1984a, b, 1985), and that less sonorous consonants such as $/ \mathrm{t} \mathrm{d} \mathrm{s} \mathrm{n} /$ are coarticulated less with neighboring vowels than more sonorous consonants such as /h/ (Keating, Lindblom, Lubker, \& Kreiman, 1994). However, some studies by Recasens (1984a, 1989) have indicated smaller V-to-V effects on $/ \mathrm{i} /$ than on /a/, but in the context of intervening lingual consonants (i.e., $/ \mathrm{t}, \mathrm{J} /$ ), which impose articulatory constraints on 
the degree of V-to- $\mathrm{V}$ coarticulation. The current finding extends this relation to V-to-V coarticulation with an intervening bilabial consonant $/ \mathrm{b} /$, which imposes less articulatory constraints on V-to-V coarticulation. ${ }^{5}$

This pattern also shows the resistance-aggression agreement: segments that resist coarticulation with neighbors also exert strong influence on them. While /i/ shows greater coarticulatory resistance to /a/ than vice versa, we can also see that /i/ shows greater coarticulatory aggression than $/ \mathrm{a} /$ in that $/ \mathrm{a} /$ coarticulates more with $/ \mathrm{i} /$ than vice versa.

\section{Summary and discussion}

\subsection{Coarticulatory reduction as a function of accent}

The coarticulatory patterns examined in this study generally support the hypothesis that vowels are coarticulated less when they are accented than unaccented. This is generally true for both carryover and anticipatory (paradigmatic) coarticulation, as well as for reciprocal (syntagmatic) coarticulation in the case of postboundary accent $\left(\mathrm{V}_{2}\right)$ effect. It has previously been reported that within a word, lexically stressed vowels show greater coarticulatory reduction than lexically unstressed ones (e.g., Fowler, 1981; Magen, 1997 for English; Nicolaidis, 1999 for Greek). The corpus of data studied here shows that sentence-level stress also induces such coarticulatory reduction in V-to-V coarticulation in English, supporting the hypothesis regarding accent-induced coarticulatory reduction.

\subsubsection{Duration and accent-induced coarticulatory resistance}

In this study, it was found that accented domain-initial vowels $\left(\mathrm{V}_{2}\right)$ are associated with not only coarticulatory reduction but also longer V-to-V interval. However, the results of ANCOVAs for reciprocal coarticulation showed that the effect of $\mathrm{V}_{2}$ accent on coarticulation remains significant even after the durational influence is factored out. This suggests that the accent-induced coarticulatory reduction is in part due to duration-independent coarticulatory resistance.

\subsection{Coarticulatory reduction across a prosodic boundary}

Another significant finding of this study is that vowels are coarticulated less with each other across higher prosodic boundaries than across lower ones, though there is an asymmetry between

\footnotetext{
${ }^{5}$ If we follow Lindblom's (1983) hypothesis about the inverse relationship between degree of coarticulatory resistance and degree of sonority, a question arises as to why sonority matters. One explanation may be that less sonorous vowels (e.g., high vowel $/ \mathrm{i} /$ ) are produced with a relatively narrower channel between the tongue body and the palate than with more sonorous vowels (e.g., low vowel /a/). The requirement of articulatory precision to make such a narrower channel for high vowels may also entail coarticulatory resistance to neighboring vowels. Alternatively, however, the observed vowel difference in coarticulation may have nothing to do with degree of sonority, but rather it may reflect constraints driven by the vowel system of English. That is, /i/ is associated with less degree of coarticulation than /a/, perhaps because /i/ occurs in a dense neighborhood of the English vowel space whereas /a/ appears in a relatively sparse neighborhood. This is reminiscent of Manuel's $(1990,1999)$ proposal that coarticulatory resistance can be observable when coarticulation would result in the blurring or confounding of phonetic contrasts.
} 
domain-initial and domain-final vowels (see below). The results lend support to the boundaryinduced coarticulatory reduction hypothesis.

\subsubsection{Asymmetry between domain-initial and domain-final vowels}

Carryover coarticulation (for domain-initial target vowels) showed a significant boundary effect at three timepoints $\left(\frac{1}{4} \mathrm{~B}, \frac{3}{4} \mathrm{~B}, \mathrm{~V}_{2}\right.$ onset) for both $/ \mathrm{Ha} /$ and $/ \mathrm{Hi} /$. On the other hand, anticipatory coarticulation showed an effect only for $/ \mathrm{a} \# /$ at one timepoint $\left(\frac{3}{4} \mathrm{~V}_{1}\right)$ in the tongue backness $(x)$ dimension and at two timepoints $\left(\mathrm{V}_{1}\right.$ end and $\left.\frac{1}{4} \mathrm{~B}\right)$ in the tongue height $(y)$ dimension. This observation allows us to infer that domain-initial vowels are more sensitive to coarticulatory variation as a function of boundary than domain-final vowels. ${ }^{6}$

\subsubsection{Duration and boundary-induced coarticulatory resistance}

It was found that the $\mathrm{V}$-to- $\mathrm{V}$ interval varies with the level of prosodic boundary-it was longer across higher prosodic boundaries than across lower ones. The results of ANCOVAs for reciprocal coarticulation showed that when this durational factor is figured in, the boundary effect becomes non-significant for $/ \mathrm{i} \# \mathrm{a} /$ while $/ \mathrm{a} \# \mathrm{i} /$ still shows duration-independent coarticulatory resistance associated with a strong prosodic boundary. This suggests that the durational variation is only partially responsible for the boundary-induced coarticulatory variation. The coarticulatory patterning and the durational variation appear to be influenced independently but similarly by the prosodic boundary. In other words, there is some degree of covariance between the two variables, but not an absolute causal relationship from duration to coarticulation. ${ }^{7}$

\subsubsection{Accent-vs. boundary-induced coarticulatory reduction}

Accent- and boundary-induced coarticulatory patterns show a similar effect, in that they both support the coarticulatory reduction hypothesis. However, there are also some differences between the two factors. First, robust accent-induced coarticulatory reduction was generally found regardless of whether the target vowel was domain-initial or domain-final, whereas domaininitial vowels showed greater coarticulatory sensitivity to the boundary than domain-final vowels. Second, the accent-induced coarticulatory pattern could not be accounted for by a duration

\footnotetext{
${ }^{6}$ This inference is supported by a larger effect size of the boundary factor for domain-initial vowels than for domainfinal vowels, as estimated by eta-squared values (cf. Sheskin, 2000, pp. 553-556). For example, in the $x$ dimension, the eta-squared value is larger for initial $/ \mathrm{a} /$ at $\mathrm{V}_{2}$ onset than for final $/ \mathrm{a} /$ at $\mathrm{V}_{1}$ end (0.903 vs. 0.464); in the $y$ dimension, it is also larger for initial /a/ than for final /a/ (0.692 vs. 0.611). The difference becomes even clearer when we consider /i/. In the $y$ dimension, the eta-squared value is substantially larger for initial $/ \mathrm{i} /$ at $\mathrm{V}_{2}$ onset $(0.601)$ as compared to final $/ \mathrm{i} /$ at $\mathrm{V}_{1}$ end (0.141). (In the $x$ dimension, no significant boundary effect was found for either initial or final /i/).

${ }^{7}$ One important caveat that must be considered here is that this interpretation is based on the results of ANCOVAs only on reciprocal (syntagmatic) coarticulation measures. The comparable statistical tests on carryover and anticipatory (paradigmatic) coarticulation measures would have either falsified or reinforced this interpretation. However, it is difficult to run ANCOVAs on such paradigmatic measures in a compatible way: in this study paradigmatic coarticulation was measured between test and control conditions coming from two different utterances (one containing the test vowels $\left(\mathrm{V}_{1} \neq \mathrm{V}_{2}\right)$ and one with the control vowels $\left(\mathrm{V}_{1}=\mathrm{V}_{2}\right)$ ). Therefore, it is not straightforward to decide what duration to use as a covariate.
} 
factor, whereas the boundary-induced coarticulatory patterning was attributable at least in part to the boundary-induced durational variation.

\subsection{Strengthening and coarticulatory reduction}

In Cho (2002), the effects of accent and boundary on the maximum tongue position were reported, showing that strengthening effects vary with tongue dimensions ( $x$ vs. $y$ ), vowel type (/i/ vs. $/ \mathrm{a} /$ ) and prosodic factors (accent vs. boundary). On the one hand, the accent-induced strengthening effect observed in the maximum tongue position was robust in the tongue height $(y)$ dimension for $/ \mathrm{a} /$ (lower tongue position for accented $/ \mathrm{a} /$ ), but in the tongue backness $(x)$ dimension for $/ \mathrm{i} /$ (fronter tongue position for accented /i/). On the other hand, the boundaryinduced strengthening effect was found robustly in domain-final position, but not uniformly in domain-initial position. This section discusses the extent to which coarticulatory reduction is related to the strengthening pattern found in the tongue maximum position.

First, consider the accent effect. In the present study, domain-initial / $\mathrm{Ha} /$ and domain-final /i\#/ manifested accent-induced coarticulatory reduction in the tongue height $(y)$ and backness $(x)$ dimensions, respectively. This is in line with the strengthening patterns found in the maximum tongue position (Cho, 2002). However, other cases showed no such conformity: domaininitial $/ \mathrm{Hi} /$ and domain-final $/ \mathrm{a} \# /$ showed no effect in the same tongue dimension as found in the maximum tongue position. This suggests that the accent-induced coarticulatory reduction is to some extent related to the articulatory strengthening effect (found in the maximum tongue position), but not uniformly.

The pattern in boundary-induced coarticulatory reduction, however, demonstrates no evidence for its direct relationship with the strengthening pattern in the maximum tongue position. That is, although domain-initial vowels in \#CV are not associated with robust articulatory strengthening of the maximum tongue position (Cho, 2002), it is in domain-initial positions where both /a/ and /i/ show coarticulatory reduction (see Section 4.2). It appears that boundary-induced coarticulatory reduction in domain-initial vowels is not a direct consequence of articulatory strengthening, at least not related to the maximum tongue position. Boundary-induced coarticulatory reduction can then be considered another form of prosodically conditioned strengthening.

It is certainly the case that some boundary-induced phonetic phenomena cannot be considered as separate phonetic events (e.g., the covariance between the V-to-V interval and the boundaryinduced coarticulatory patterning). This does not necessarily mean that all phonetic correlates of prosodic structure are directly related to each other. In fact, the mismatch between boundaryinduced coarticulatory reduction and strengthening found for the maximum tongue position suggests that they are independent phonetic events. Segments at the edges of prosodic boundaries may be strengthened in multiple ways, whether related or not. Multiple phonetic cues may then be marshalled to heighten phonetic clarity of segments occurring in prosodically strong locations, ultimately marking the high-level prosodic structure. The strengthening of the maximum tongue position and coarticulatory reduction may contribute to such phonetic clarity independently. Thus, in a broad sense, just as the extreme articulation evidenced from the maximum tongue position can be regarded as one type of prosodically conditioned strengthening, so too can the 
boundary-induced coarticulatory reduction be seen as another type of prosodically conditioned strengthening.

\subsection{Coarticulatory resistance vs. coarticulatory aggression}

In this study, only some evidence was found to favor the accent-induced coarticulatory aggression hypothesis: for the target vowel /i\#/, there is a significant interaction among factors, showing a clear three-way distinction (IP $<\mathrm{ip}<\mathrm{Wd}$ ) only when the following (encroaching) vowel is unaccented. This indicates that the accentuation of the neighboring vowel does influence the target vowel's articulation at least to some degree. However, there was no main effect of the accent of the neighboring vowel, nor were there significant interactions between the accent of the target vowel and the accent of the neighboring vowel. This suggests that accented vowels do not influence neighboring vowels' articulation in the direction that we expected, namely, that a vowel would be coarticulated more with a neighboring accented than with an unaccented vowel.

This finding does not conform to the $\mathrm{V}$-to- $\mathrm{V}$ coarticulatory aggression effect of stressed vowels on neighboring unstressed vowels within a word (e.g., Fowler, 1981). This appears also incompatible with the view that coarticulatory resistance can be related to coarticulatory aggression, as proposed under the window model (Keating, 1990). There are at least two possible reasons. First, the previous results were based on lexical stress effects on neighboring vowels within a word, while the present results were based on accent effects across a word or a phrase boundary. Since the V-to-V interval is likely to be longer across a word or a phrase boundary than across a syllable boundary within a word, the effect of stress may not spread into a neighboring segment. Second, coarticulatory aggression may not be directly associated with coarticulatory resistance, especially in V-to-V coarticulation. Accented vowels are hyperarticulated showing an extreme tongue position (e.g., lower tongue position for /a/) (cf. de Jong, 1995a). However, hyperarticulation under accent may not necessarily induce a vowel to be more similar to (or coarticulate more with) an accented neighboring vowel across boundaries larger than a syllable boundary, at least not in a straightforward way.

Several articulatory possibilities can be thought of as underlying dynamical mechanisms for lower tongue position associated with the accented /a/. The activation of the lowering movement may come earlier so that the influence of the accented /a/ can be observed during the production of preceding vowel /i/, in which case we expect coarticulatory aggression. However, the hyperarticulation can also be achieved without an earlier activation of the tongue lowering movement. The tongue lowering movement can start at the same point in time for both accented and unaccented vowels, but under accent it may simply take longer to achieve the assumed target (in the spirit of Lindblom's undershoot theory). It is also possible that the tongue lowering movement reaches its hyperarticulated position faster without either an earlier activation or a longer duration involved in achieving the extreme target. While testing these possibilities is outside the scope of this study, they at least indicate that accented vowels may not necessarily induce coarticulatory aggression on neighboring vowels, which is presumably why no aggression effect was found in the present study.

\subsection{Revisions to the window model}

In this study, larger coarticulation was found for $/ \mathrm{a} /$ than for $/ \mathrm{i} /$. The asymmetry due to segmental identity can be accounted for by the notion of "window" (Keating, 1990), which 
was proposed to relate contrast, coarticulatory resistance, and coarticulatory aggression by making phonetic targets vary within a specified range (i.e., window) rather than simply having fixed values. Segments with a narrower window (such as /i/) will have greater coarticulatory resistance than segments with a wider window (such as $/ \mathrm{a} /$ ). A narrower window is assumed to influence the position in wider windows of neighboring segments (coarticulatory aggression), such that the model equates at least weakly coarticulatory resistance and aggression. Indeed, in the present study, it was found that / $\mathrm{i}$ ( with a narrower window) is less coarticulated with /a/ (with a wider window) than the other way around. This is consistent with the resistance-aggression relationship, as far as the inherent segmental effects are concerned.

While the model captures inherently induced coarticulatory variations by relating coarticulatory resistance to coarticulatory aggression, the data presented in this paper suggest several phenomena that should be taken into account in the current window model. First, the results showed that coarticulatory resistance arising from a prosodic factor (i.e., accent) does not necessarily induce coarticulatory aggression, unlike effects seen from an inherent segmental factor. Therefore, a mechanism should be devised that dissociates prosodically induced coarticulatory resistance from coarticulatory aggression while associating inherently induced coarticulatory resistance with coarticulatory aggression.

Another factor not considered in the original window model was coarticulatory variation which might result from prosodic variation (cf. Keating, 1996). The original model allows only one fixed window size for a segment. Keating (1990, p. 456) explains "Windows are determined empirically on the basis of context, but once determined are not themselves contextually varied... Information about the possibilities for contextual variation is already built into that one window." However, prosodically conditioned coarticulatory variations appear to require a flexible window, such that the window size should vary depending on prosodic conditions.

A possible solution to the problem of prosodic influences on window size has been proposed by Guenther (1995, see Guenther et al., 1998 for a recent extension of the model in shifting from articulatory to auditory perceptual targets). As noted by Keating (1996), Guenther's model provides the basis for modifying Keating's window model in a way that allows re-sizing of the window to accommodate influences from various linguistic and extralinguistic factors. Crucially relevant to the present study is the idea that the window-like range of targets can be re-sized, roughly in proportion to the scale of Lindblom's (1990) hypo- to hyperarticulation. Hyperarticulation can be implemented by smaller windows, reflecting less contextual variation, or greater coarticulatory resistance. Based on this, Guenther also suggests that hyperarticulation due to accent can be accounted for by a decrease in contextual variation induced by a smaller range of targets. Here coarticulatory resistance is still expected as the local hyperarticulation predicts (e.g.. de Jong, 1995a), but not driven by the prominence maximization principle, but rather by shrinking windows.

Byrd's (1996) phase window model provides mechanisms that may capture prosodically conditioned window size. The phase window is the range of possible values in which intergestural overlap is implemented. It can be weighted by various linguistic/extralinguistic factors, or influencers. (See Cho (2001) for a discussion.) Similarly, multiple influencers can collectively affect the window size and determine the final active region of the window. Then, prosodic factors such 
as accent and boundary may serve as influencers weighting the active region of the window, which leads to accent- or boundary-induced coarticulatory variation.

Another crucial point to be considered in modifying the window model is the directionality of the window's re-sizing. While Guenther's model does not have a mechanism that specifies the direction of the window's shrinking that may arise from prosodically conditioned articulatory strengthening, the results of this study suggest that the window shrinks in a direction that leads to full achievement of the segment's target; i.e., hyperarticulation of the segment's featural target. For example, the window for $/ \mathrm{a} /$ in the tongue vertical $(y)$ dimension shrinks downwards, resulting in the hyperarticulation of $[+$ low $]$ and the resistance to the tongue raising; and the window for $/ \mathrm{i} /$ shrinks in a anterior direction, causing the hyperarticulation of [-back] and the resistance to the tongue backing.

Thus far, some crucial points have been outlined that should be incorporated into the current window model in order to capture prosodically conditioned segmental variation. However, there are numerous other factors that may also affect the window and many other unresolved issues may be involved. The most fundamental question is how the effects of individual influencers combine to determine the final active region of the window. For instance, the relationship between duration and prosodic conditions have not been considered. As suggested by the results regarding duration, stress and prosodic boundary factors must not be treated the same, since they show different relationships between coarticulation and duration. Other factors to be considered also include speech rate and speaker variation. Answering these questions is beyond the scope of this work, but the hope is that a discussion of problems identified in the present study will offer a framework from which further research on coarticulation can benefit.

\section{Conclusion}

Results in this study suggest that the degree of $\mathrm{V}$-to- $\mathrm{V}$ coarticulation varies as a function of prosodic conditions such as the sentential level stress (accent) and the level of prosodic boundary: Vowels in a prosodically strong location resist their coarticulation with neighboring vowels in a systematic fashion. This implies that phonetic realizations are governed by high level prosodic conditions, and that the prosodically conditioned phonetic patterns may in turn signal high level prosodic structures. Coarticulatory reduction in prosodically strong positions may give rise to heightened phonetic clarity, which can be interpreted as enhancing linguistic contrast, both syntagmatically (structurally) and paradigmatically (lexically or phonemically). For example, heightened phonetic clarity can render a sound more distinct from neighboring segments (an enhancement of syntagmatic contrast), and it can also make the sound distinct from other contrastive sounds in the sound system of the language (an enhancement of paradigmatic contrast). These two effects appear to be compatible. It is possible that phonetic clarity arising from strengthening can render the segment in prosodically strong locations more prominent than neighboring segments and, at the same time, make the segment maximally distinctive among contrastive sounds.

It was proposed that coarticulatory resistance is not simply a by-product of articulatory strengthening (as measured by maximum tongue position), but rather it can be better 
characterized as another type of strengthening that occurs independently in prosodically strong locations, contributing to marking prosodic structure. It is plausible that when a speaker aims for phonetic clarity, especially in positions that are strong with respect to the prosody of his/her intended message, $\mathrm{s} /$ he demonstrates various strengthening effects as a result of the speaker's global effort to mark the prosodic position (e.g., extreme articulation as seen in the maximum tongue position and coarticulatory resistance).

Prosodically conditioned strengthening as a prominence enhancing strategy can also be thought of as facilitating lexical processing and sentence comprehension. It has been suggested in the literature that accented words are processed more efficiently in spoken word recognition than unaccented words (Shields, McHugh, \& Martin, 1974; Cutler, 1976; Cutler \& Foss, 1977). Furthermore, recent psycholinguistic studies have suggested that the appropriate prosodic cues for boundaries can facilitate sentence comprehension (e.g., Sanderman, 1996; Sanderman \& Collier, 1997; Schafer, 1997 among others) and word segmentation (Kim, 2003). It has also been shown that lexical segmentation and lexical access is facilitated when a word occurs phrase-initially, as opposed to when it occurs phrase-medially (Christophe, Gout, \& Morgan, 2001; McQueen \& Cho, 2003). This is likely due to phonetic clarity arising from prosodically conditioned strengthening phenomena (including coarticulatory resistance) which facilitates lexical processing. The present study warrants future psycholinguistic studies to investigate the roles of various phonetic events associated with prosodic structure in speech comprehension.

\section{Acknowledgements}

The author would like to thank Sun-Ah Jun and Patricia Keating for their valuable input to this paper. The author also thank Peter Ladefoged, Bruce Hayes, Jody Kreiman, Adam Albright, Rebecca Brown Scarborough, James McQueen, Tania Zamuner, and Lalita Murty for their comments and suggestions; editor Doug Whalen, Cécile Fougeron, and two anonymous reviewers for their constructive and critical comments on an earlier version of this paper. A preliminary version of this paper appeared in Chapter 4 of the author's UCLA Ph.D. dissertation. This work has been supported by the Max Planck Institute for Psycholinguistics and the NSF doctoral improvement grant (BCS-0001716) to the author and Patricia Keating.

\section{Appendix A. The speech corpus}

The speech corpus with different sets containing [bi\#bi], [ba\#bi], and [bi\#ba]. (See Table 1 for [ba\#ba].) These sequences occur in sentences in a mini discourse situation which induces a variety of accent-placement and prosodic boundary patterns. Note that L\% refers to the IP boundary which is marked by a low (L) boundary tone; $\mathrm{L}-$ refers to a phrasal (low) tone that marks the end of the ip; $\mathrm{L}-$ before a boundary tone $(\mathrm{L} \%)$ means that the intonational pattern is maintained low before the boundary tone; and $\mathrm{H}^{*}$ refers to a nuclear-pitch accent marked by a high $(\mathrm{H})$ pitch on an accented word. 


\section{A.1. [bi\#bi] sequence}

\# = Word boundary
(a) Acc.-Unacc.
A: Did you say "Donna $\mathbf{D}$. beeped at him last night"?

B: No, "Donna B. \# beeped at him "

rendition :

$(\mathrm{L}+) \mathrm{H}^{*}$

$\mathrm{L}-\mathrm{L} \%$

(b)Unacc.-Acc. $\quad$ A: Did you say "Donna B. peeped at him last night"?

B: No, "Donna B. \# beeped at him "

rendition :

(c) Acc.-Acc.

$(\mathrm{L}+) \mathrm{H}^{*} \quad \mathrm{~L}-\mathrm{L} \%$

rendition:

A: You know what? Anna B. \# beeped at him.

(d)Unacc.-Unacc.

$(\mathrm{L}+) \mathrm{H}^{*} \mathrm{H}^{*}$

$\mathrm{L}-\mathrm{L} \%$

rendition: $\quad(\mathrm{L}+) \mathrm{H}^{*} \quad \mathrm{~L}-\mathrm{L} \%$

A: Did you say "Anna B. beeped at him last night"?

B: No, "Donna B. \# beeped at him "

\# = Intermediate or Intonational Phrase boundaries (ip or IP)

(e) Acc.-Unacc. $\quad$ A: Did you say "Donna D. beeped at Ann last night"?

B: No, "Donna B. \# beeped at Al "

renditions :

$(\mathrm{L}+) \mathrm{H} * \mathrm{~L}-(\mathrm{L} \%) \quad(\mathrm{L}+) \mathrm{H}^{*} \mathrm{~L}-\mathrm{L} \%$

(f) Unacc.-Acc. $\quad$ A: Did you say "Anna B. peeped at him last night"?

B: No, "Donna B. \# beeped at him "

renditions :

$\left(\mathrm{L}+\mathrm{H}^{*} \mathrm{~L}-(\mathrm{L} \%)(\mathrm{L}+)^{*} \quad \mathrm{~L}-\mathrm{L} \%\right.$

(g) Acc.-Acc. A: Did you say "Donna D. peeped at him last night"?

B: No, "Donna B. \# beeped at him "

renditions :

$\mathrm{H}^{*} \mathrm{~L}-(\mathrm{L} \%) \quad \mathrm{H}^{*} \quad \mathrm{~L}-\mathrm{L} \%$

(h) Unacc.-Unacc. A: Did you say "Anna B. beeped at Ann last night"?

B: No, "Donna B. \# beeped at Al "

renditions:

$$
(\mathrm{L}+) \mathrm{H}^{*} \mathrm{~L}-(\mathrm{L} \%) \quad(\mathrm{L}+) \mathrm{H}^{*} \mathrm{~L}-\mathrm{L} \%
$$

\section{A.2. [ba\#bi] sequence}

\# = Word boundary
(a) Acc.-Unacc.
A: Did you say "Little Boo beeped at him last night"?
B: No, "Little Bah \# beeped at him"
rendition :
$\mathrm{L}-\mathrm{L} \%$

$(\mathrm{L}+) \mathrm{H}^{*}$

(b)Unacc.-Acc. $\quad$ A: Did you say "Little Bah peeped at him"?

B: No, "Little Bah \# beeped at him"

rendition :

$(\mathrm{L}+) \mathrm{H}^{*} \quad \mathrm{~L}-\mathrm{L} \%$

(c) Acc.-Acc.

A: You know what? Little Bah \# beeped at him.

rendition :

$(\mathrm{L}+) \mathrm{H}^{*} \quad \mathrm{H}^{*} \quad \mathrm{~L}-\mathrm{L} \%$

(d)Unacc.-Unacc. $\quad$ A: Did you say "Big Bah beeped at him last night"?

B: No, "Little Bah \# beeped at him "

rendition :

$\left(\mathrm{L}+\mathrm{H}^{*}\right.$

$\mathrm{L}-\mathrm{L} \%$

\# = Intermediate or Intonational Phrase boundaries (ip or IP)

(e) Acc.-Unacc. $\quad$ A: Did you say "Little Boo beeped at Ann last night"?

B: No, "Little Bah \# beeped at Al "

renditions :

$$
(\mathrm{L}+) \mathrm{H} * \mathrm{~L}-(\mathrm{L} \%) \quad(\mathrm{L}+) \mathrm{H}^{*} \mathrm{~L}-\mathrm{L} \%
$$

(f) Unacc.-Acc. $\quad$ A: Did you say "Big Bah peeped at him last night"?

B: No, "Little Bah \# beeped at him "

renditions :

$(\mathrm{L}+) \mathrm{H}^{*} \mathrm{~L}-(\mathrm{L} \%) \quad(\mathrm{L}+) \mathrm{H}^{*} \quad \mathrm{~L}-\mathrm{L} \%$ 
(g) Acc.- Acc. $\quad$ A: Did you say "Little Boo peeped at him last night "?

B: No, "Little Bah \# beeped at him "

renditions:

$(\mathrm{L}+) \mathrm{H} * \mathrm{~L}-(\mathrm{L} \%) \quad(\mathrm{L}+) \mathrm{H}^{*} \quad \mathrm{~L}-\mathrm{L} \%$

(h) Unacc.-Unacc. A: Did you say "Big Bah beeped at Ann last night "?

B: No, "Little Bah \# beeped at Al "

renditions:

$\left(\mathrm{L}+\mathrm{H}^{*} \mathrm{~L}-(\mathrm{L} \%) \quad(\mathrm{L}+)^{*} \mathrm{~L}-\mathrm{L} \%\right.$

\section{A.3. [bi\#ba] sequence}

\# = Word boundary

(a) Acc.-Unacc. $\quad$ A: Did you say "Donna D. bopped the girl last night"?

B: No, "Donna B. \# bopped the girl"

rendition :

$\left(\mathrm{L}+\mathrm{H}^{*} \quad \mathrm{~L}-\mathrm{L} \%\right.$

(b)Unacc.-Acc. $\quad$ A: Did you say "Donna B. popped the girl "?

B: No, "Donna B. \# bopped the girl"

rendition :

$(\mathrm{L}+) \mathrm{H}^{*} \quad \mathrm{~L}-\mathrm{L} \%$

(c) Acc.-Acc.

A: You know what? Donna B. \# bopped the girl.

rendition:

$\mathrm{H}^{*} \quad \mathrm{H}^{*} \quad \mathrm{~L}-\mathrm{L} \%$

(d)Unacc.-Unacc. $\quad$ A: Did you say "Anna B. bopped the girl last night"?

B: No, "Donna B. \# bopped the girl "

rendition :

$\left(\mathrm{L}+\mathrm{H}^{*}\right.$

$\mathrm{L}-\mathrm{L} \%$

\# = Intermediate or Intonational Phrase boundaries (ip or IP)

(e) Acc.-Unacc. $\quad$ A: Did you say "Donna D. bopped the boy last night"?

B: No, "Donna B. \# bopped the girl "

renditions:

$(\mathrm{L}+) \mathrm{H} * \mathrm{~L}-(\mathrm{L} \%) \quad(\mathrm{L}+) \mathrm{H}^{*} \mathrm{~L}-\mathrm{L} \%$

(f) Unacc.-Acc.

A: Did you say "Anna B. popped the girl last night"?

B: No, "Donna B. \# bopped the girl "

renditions :

$(\mathrm{L}+) \mathrm{H}^{*} \mathrm{~L}-(\mathrm{L} \%)(\mathrm{L}+) \mathrm{H}^{*} \quad \mathrm{~L}-\mathrm{L} \%$

(g) Acc.-Acc. $\quad$ A: Did you say " Donna D. popped the girl last night"?

B: No, "Donna B. \# bopped the girl "

renditions:

$(\mathrm{L}+)^{*} \mathrm{~L}-(\mathrm{L} \%) \quad(\mathrm{L}+) \mathrm{H}^{*} \quad \mathrm{~L}-\mathrm{L} \%$

(h) Unacc.-Unacc. A: Did you say "Anna B. bopped the boy last night"?

B: No, "Donna B. \# bopped the girl "

renditions:

$\left(\mathrm{L}+\mathrm{H}^{*} \mathrm{~L}-(\mathrm{L} \%) \quad(\mathrm{L}+) \mathrm{H}^{*} \mathrm{~L}-\mathrm{L} \%\right.$

\section{Appendix B}

Summary of main effects in repeated measures ANOVAs are given in Tables 2-4.

Table 2

Summary of main effects in repeated measures ANOVAs for carryover coarticulation

\begin{tabular}{lllll}
\hline Vowel type & Dimension & $\frac{3}{4} \mathrm{~B}$ & $\mathrm{~V}_{2}$ onset & $\frac{1}{4} \mathrm{~V}_{2}$ \\
\hline (a) Accent, $F(1,5)$ & & & \\
/i\#ba $/$ & $X$-distance & $F=4.849^{\text {tr }}$ & $F=4.583$ & $F=1.328$ \\
& $Y$-distance & $F=7.650^{*}$ & $F=10.439^{*}$ & $F=5.849^{\operatorname{tr}}$ \\
/a\#bi/ & $X$-distance & $F=4.546$ & $F=5.505^{\text {tr }}$ & $F=3.755$ \\
& $Y$-distance & $F=2.631$ & $F=6.103^{\text {tr }}$ & $F=10.884^{*}$
\end{tabular}


Table 2 (continued)

\begin{tabular}{|c|c|c|c|c|}
\hline Vowel type & Dimension & $\frac{3}{4} \mathrm{~B}$ & $\mathrm{~V}_{2}$ onset & $\frac{1}{4} V_{2}$ \\
\hline \multicolumn{5}{|c|}{ (b) Boundary (F-values with Huynh-Feldt corrected $d f$ ) } \\
\hline \multirow[t]{2}{*}{ ii\#ba/ } & $X$-distance & $F(1.29,6.43)=61.723^{* *}$ & $F(1.50,7.52)=46.329^{* *}$ & $F(1.10,5.55)=2.008$ \\
\hline & $Y$-distance & $F(2,10)=12.150^{* *}$ & $F(2,10)=10.210^{* *}$ & $F(2,10)=1.431$ \\
\hline \multirow{2}{*}{$/ \mathbf{a} \# \mathbf{b i} /$} & $X$-distance & $F(2,10)=2.361$ & $F(2,10)=0.963$ & $F(2,10)=0.002$ \\
\hline & $Y$-distance & $F(2,10)=9.182^{* *}$ & $F(2,10)=7.542^{* *}$ & $F(1.80,9.01)=1.729$ \\
\hline
\end{tabular}

Table 3

Summary of main effects in repeated measures ANOVAs for anticipatory coarticulation

\begin{tabular}{|c|c|c|c|c|}
\hline Vowel type & Dimension & $\frac{3}{4} \mathrm{~V}_{1}$ & $V_{1}$ end & $\frac{1}{4} \mathrm{~B}$ \\
\hline \multicolumn{5}{|c|}{ (a) Accent, $F(1,5)$} \\
\hline \multirow[t]{2}{*}{ /ä\#bi/ } & $X$-distance & $F=8.399^{*}$ & $F=9.064^{*}$ & $F=8.332^{*}$ \\
\hline & $Y$-distance & $F=0.411$ & $F=0.072$ & $F=0.543$ \\
\hline \multirow[t]{2}{*}{ /i $\# \mathrm{ba} /$} & $X$-distance & $F=33.222^{* *}$ & $F=15.270^{*}$ & $F=7.790^{*}$ \\
\hline & $Y$-distance & $F=0.837$ & $F=2.399$ & $F=0.665$ \\
\hline \multicolumn{5}{|c|}{ (b) Boundary (F-values with Huynh-Feldt corrected df) } \\
\hline \multirow[t]{2}{*}{ /a\#bi/ } & $X$-distance & $F(2,10)=4.959^{*}$ & $F(1.55,7.77)=4.324^{\text {tr }}$ & $F(1.12,5.55)=5.252^{\operatorname{tr}}$ \\
\hline & $Y$-distance & $F(2,10)=0.566$ & $F(1.26,6.30)=7.971^{*}$ & $F(1.08,5.41)=10.556^{*}$ \\
\hline \multirow[t]{2}{*}{ /i $\# \mathrm{ba} /$} & $X$-distance & $F(2,10)=0.214$ & $F(1.91,9.54)=0.667$ & $F(2,10)=0.549$ \\
\hline & $Y$-distance & $F(2,10)=2.469$ & $F(2,10)=3.428^{\operatorname{tr}}$ & $F(1.33,6.69)=0.946$ \\
\hline
\end{tabular}

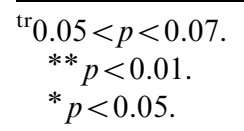

Table 4

Summary of main effects in repeated measures ANOVAs for reciprocal coarticulatory effect

\begin{tabular}{llll}
\hline & $\frac{3}{4} \mathrm{~V}_{1}-\frac{1}{4} \mathrm{~V}_{2}$ & $\mathrm{~V}_{1}$ end- $\mathrm{V}_{2}$ onset & $\frac{1}{4} \mathrm{~B}-\frac{3}{4} \mathrm{~B}$ \\
\hline (a) $V_{1}$ accent $F(1,5)$ & & & \\
$X$-distance & $F=1.502$ & $F=4.099$ & $F=6.249^{\operatorname{tr}}$ \\
$Y$-distance & $F=5.134$ & $F=2.034$ & $F=7.742^{*}$ \\
& & & \\
(b) $V_{2}$ accent, $F(1,5)$ & $F=47.194^{* *}$ & $F=88.119^{* *}$ & $F=17.647^{* *}$ \\
$X$-distance & $F=20.407^{* *}$ & $F=48.877^{* *}$ & $F=37.852^{* *}$ \\
$Y$-distance & & \\
(c) Prosodic boundary, $F$-values with Huynh-Feldt corrected $d f$ & & $F(2,10)=3.270^{\operatorname{tr}}$ \\
$X$-distance & $F(2,10)=1.575$ & $F(2,10)=3.412^{\text {tr }}$ & $F(2,10)=3.798^{\operatorname{tr}}$ \\
$Y$-distance & $F(1.45,7.24)=2.892$ & $F(2,10)=4.882^{*}$ &
\end{tabular}

\footnotetext{
${ }^{\mathrm{tr}} 0.05<p<0.07$.

$*^{* *} p<0.01$.

$* p<0.05$.
} 


\section{References}

Beckman, M. E. (1986). Stress and non-stress accent. Dordrecht: Foris Publications.

Beckman, M. E., \& Edwards, J. (1994). Articulatory evidence for differentiating stress categories. In P. A. Keating (Ed.), Papers in laboratory phonology III: Phonological structure and phonetic form (pp. 7-33). Cambridge: Cambridge University Press.

Beckman, E. E., \& Elam, G. A. (1997). Guidelines for ToBI labelling, version 3.0, Ohio State University, Unpublished Manuscript.

Beckman, M. E., \& Pierrehumbert, J. (1986). International structure in Japanese and English. Phonology Yearbook, 3, 255-309.

Beddor, P. S., Harnsberger, J. D., \& Lindermann, S. (2002). Language-specific patterns of vowel-to-vowel coarticulation: Acoustic structures and their perceptual correlates. Journal of Phonetics, 30, 591-627.

Bladon, R. A., \& Nolan, F. (1977). A video-fluorographic investigation of tip and blade alveolars in English. Journal of Phonetics, 5, 185-193.

Byrd, D. (1996). A phase window framework for articulatory timing. Phonology, 13, 139-169.

Byrd, D., \& Saltzman, E. (2003). The elastic phrase: Modeling the dynamics of boundary-adjacent lengthening. Journal of Phonetics, 31, 149-180.

Cho, T. (2001). Effects of morpheme boundaries on intergestural timing. Evidence from Korean. Phonetica, 58, $129-162$.

Cho, T. (2002). The effects of prosody on articulation in English. New York: Routledge (Also distributed as UCLA Dissertations in Linguistics, no. 22, 2001).

Cho, T. (submitted for publication). Manifestation of prosodic structure in articulation: Evidence from lip movement kinematics in English. In S.R. Anderson, C.T. Best, L. Goldstein, \& D.H. Whalen (Eds.), Papers in Laboratory Phonology VIII. Berlin/New York: Mouton de Gruyter.

Cho, T., \& Jun, S. (2000). Domain-initial strengthening as featural enhancement: Aerodynamic evidence from Korean. Chicago Linguistics Society, 36(1), 31-44.

Cho, T., \& Keating, P. (2001). Articulatory and acoustic studies of domain-initial strengthening in Korean. Journal of Phonetics, 29, 155-190.

Christophe, A., Gout, A., \& Morgan, J. (2001). Infants and adults exploit phonological phrase boundaries on-line to drive lexical access. A paper presented in workshop prosody in processing, Utrecht institute of Linguistics OTS, Utrecht University, 5-6 July 2001.

Cutler, A. (1976). Phoneme-monitoring reaction time as a function of preceding intonation contour. Perception and Psychophysics, 20, 55-60.

Cutler, A., \& Foss, D. J. (1977). On the role of sentence stress in sentence processing. Language and Speech, 20, 1-10.

De Jong, K. (1991). The oral articulation of English stress accent. Unpublished Ph.D. Dissertation, Ohio State University.

De Jong, K. (1995a). The supraglottal articulation of prominence in English: Linguistic stress as localized hyperarticulation. Journal of the Acoustical Society of America, 97(1), 491-504.

De Jong, K. (1995b). On the status of redundant features: The case of backing and rounding in American English. In B. Connell, \& A. Arvaniti (Eds.), Phonology and phonetic evidence: Papers in laboratory phonology IV (pp. 68-86). Cambridge, UK: Cambridge University Press.

De Jong, K., Beckman, M. E., \& Edwards, J. (1993). The interplay between prosodic structure and coarticulation. Language and Speech, 36(2,3), 197-212.

Edwards, J. E., Beckman, M. E., \& Fletcher, J. (1991). The articulatory kinematics of final lengthening. Journal of the Acoustical Society of America, 89, 369-382.

Farnetani, E. (1990). V-C-V lingual coarticulation and its spatiotemporal domain. In W. J. Hardcastle, \& A. Marchal (Eds.), Speech production and speech modeling (pp. 93-130). Dordrecht: Kluwer Academic Publishers.

Farnetani, E. (1997). Coarticulation and connected speech processes. In W. J. Hardcastle, \& J. Laver (Eds.), A handbook of phonetic science (pp. 371-404). Oxford: Blackwell.

Farnetani, E., \& Recasens, D. (1993). Anticipatory consonant-to-vowel coarticulation in the production of VCV sequences in Italian. Language and Speech, 36, 279-302. 
Farnetani, E., \& Recasens, D. (1999). Coarticulation models in recent speech production theories. In W. J. Hardcastle, \& N. Hewlett (Eds.), Coarticulation: Theory, data and techniques (pp. 31-65). Cambridge, UK: Cambridge University Press.

Fougeron, C. (2001). Articulatory properties of initial segments in several prosodic constituents in French. Journal of Phonetics, 29, 109-135.

Fougeron, C., \& Keating, P. A. (1997). Articulatory strengthening at edges of prosodic domains. Journal of the Acoustical Society of America, 106(6), 3728-3740.

Fowler, C. A. (1980). Coarticulation and theories of extrinsic timing. Journal of Phonetics, 8, 113-133.

Fowler, C. A. (1981). Production and perception of coarticulation among stressed and unstressed vowels. Journal of Speech and Hearing Research, 46, 127-139.

Fowler, C. A., \& Saltzman, E. (1993). Coordination and coarticulation in speech production. Language and Speech, $36(2,3), 171-195$.

Guenther, F. H. (1995). Speech sound acquisition, coarticulation, and rate effects in a neural network model of speech production. Psychological Review, 102, 594-621.

Guenther, F. H., Hampson, M., \& Johnson, D. (1998). A theoretical investigation of reference frames for the planning of speech movements. Psychological Review, 105, 611-633.

Harrington, J., Fletcher, J., \& Roberts, C. (1995). Coarticulation and the accented/unaccented distinction: Evidence from jaw movement data. Journal of Phonetics, 23, 305-322.

Hayes, B. (1989). The prosodic hierarchy in meter. In P. Kiparsky, \& G. Youmans (Eds.), Phonetics and phonology: Rhythm and meter, Vol. I. (pp. 47-96). New York: Academic Press.

Hoole, P. (1996). Issues in the acquisition, processing, reduction and parameterization of articulographic data. Forschungsberichte des Institut für Phonetik und Sprachliche Kommunikation, München, 34, 158-173.

Huynh, H., \& Feldt, L. S. (1970). Conditions under which mean square ratios in repeated measurements designs have exact F-distributions. Journal of the American Statistical Association, 65, 1582-1589.

Jun, S.-A. (1993). The phonetics and phonology of Korean prosody. Ph.D. Dissertation, Ohio State University.

Jun, S.-A. (1998). The accentual phrase in the Korean prosodic hierarchy. Phonology, 15(2), 189-226.

Keating, P. A. (1990). The window model of coarticulation: Articulatory evidence. In J. Kingston, \& M. E. Beckman (Eds.), Papers in laboratory phonology I: Between the grammar and the physics of speech (pp. 451-470). Cambridge: Cambridge University Press.

Keating, P. A. (1996). The phonology-phonetics interface. In U. Kleinhenz (Ed.), Interfaces in phonology, studia grammatica, Vol. 41 (pp. 262-278). Berlin: Akademie Verlag.

Keating, P. A., Cho, T., Fougeron, C., \& Hsu, C. (in press). Domain-initial strengthening in four languages. In J. Local, R. Ogden, \& R. Temple (Eds.), Papers in laboratory phonology VI: Phonetic interpretations. Cambridge, UK: Cambridge University Press.

Keating, P. A., Lindblom, B., Lubker, J., \& Kreiman, J. (1994). Variability in jaw height for segments in English and Swedish VCVs. Journal of Phonetics, 22, 407-422.

Kim, S. (2003). The role of post-lexical tonal contours in word segmentation. Proceedings of the 15th International Congress of Phonetic Sciences. Barcelona, Spain.

Kirk, R. E. (1995). Experimental design: Procedures for the behavioral sciences. Pacific Grove, CA: Brooks/Cole Publishing Company.

Klatt, D. H. (1975). Vowel lengthening is syntactically determined in connected discourse. Journal of Phonetics, 3, $129-140$.

Kühnert, B., \& Nolan, F. (1999). The origin of coarticulation. In W. J. Hardcastle, \& N. Hewlett (Eds.), Coarticulation: Theory, data and techniques (pp. 1-30). Cambridge, UK: Cambridge University Press.

Liberman, M., \& Prince, A. (1977). On stress and linguistic rhythm. Linguistic Inquiry, 8, 29-336.

Lindblom, B. (1963). Spectrographic study of vowel reduction. Journal of the Acoustical Society of America, 35, 1773-1781.

Lindblom, B. (1983). Economy of speech gestures. In P. F. MacNeilage (Ed.), The production of speech (pp. 217-245). New York, NY: Springer.

Lindblom, B. (1990). Explaining phonetic variation: A sketch of the H\&H theory. In W. J. Hardcastle, \& A. Marschal (Eds.), Speech production and speech modeling (pp. 403-439). Dordrecht: Kluwer. 
Magen, H. (1997). The extent of vowel-to-vowel coarticulation in English. Journal of Phonetics, 25, 187-205.

Manuel, S. (1990). The role of contrast in limiting vowel-to-vowel coarticulation in different languages. Journal of the Acoustical Society of America, 88(3), 1286-1298.

Manuel, S. (1999). Cross-language studies: Relating language-particular coarticulation patterns to other languageparticular facts. In W. J. Hardcastle, \& N. Hewlett (Eds.), Coarticulation: Theory, data and techniques (pp. 179-198). Cambridge, UK: Cambridge University Press.

Max, L., \& Onghena, P. (1999). Some issues in the statistical analysis of completely randomized and repeated measures designs for speech, language, and hearing research. Journal of Speech, Language, and Hearing Research, 42, 261-270.

McQueen, J., \& Cho, T. (2003). The use of domain-initial strengthening in segmentation of continuous English speech. Proceedings of the 15th international congress of phonetic sciences. Barcelona, Spain, 2003.

Nicolaidis, K. (1999). The influence of stress on V-to-V coarticulation: An electropalatographic study. In J. J. Ohala, Y. Hasegawa, M. Ohala, D. Granville, \& A. C. Bailey (Eds.), Proceedings of the 14th international congress of phonetic sciences (pp. 1087-1090). New York: American Institute of Physics.

Öhman, S. (1966). Coarticulation in VCV utterances: Spectrographic measurements. Journal of the Acoustical Society of America, 39, 151-168.

Papcun, G., Hochberg, J., Thomas, T. R., Laroche, F., Zacks, J., \& Levy, S. (1992). Inferring articulation and recognizing gestures from acoustics with a neural network trained on X-ray microbeam data. Journal of the Acoustical Society of America, 92(2), 688-700.

Perkell, J. S., Cohen, M. H., Svirsky, M. A., Matthies, M. L., Garabieta, I., \& Jackson, M. T. T. (1992). Electromagnetic midsagittal articulometer systems for transducing speech articulatory movements. Journal of the Acoustical Society of America, 92, 3078-3096.

Recasens, D. (1984a). Vowel-to-vowel coarticulation in Catalan VCV sequences. Journal of the Acoustical Society of America, 76, 1624-1635.

Recasens, D. (1984b). V-to-C coarticulation in Catalan VCV sequences: An articulatory and acoustical study. Journal of Phonetics, 12, 61-73.

Recasens, D. (1985). Coarticulatory patterns and degrees of coarticulatory resistance in Catalan CV sequences. Language and Speech, 28, 97-114.

Recasens, D. (1987). An acoustic analysis of V-to-C and V-to-V coarticulatory effects in Catalan and Spanish VCV sequences. Journal of Phonetics, 15, 299-312.

Recasens, D. (1989). Long range coarticulation effects for tongue dorsum contact in VCVCV sequences. Speech Communication, 8, 293-307.

Sanderman, A. (1996). Prosodic phrasing: Production, perception, acceptability and comprehension. Ph.D. Dissertation, Technische Universiteit Eindhoven.

Sanderman, A., \& Collier, R. (1997). Prosodic phrasing and comprehension. Language and Speech, 40, 391-409.

SAS (1999). StatView (Version 5) SAS Institute Inc.

Schafer, A. J. (1997). Prosodic parsing: The role of prosody in sentence comprehension. Doctoral Dissertation, University of Massachusetts.

Schoenle, P. W. (1988). Elektromagnetische artikulographie. Berlin: Springer.

Schoenle, P. W., Mueller, C., \& Wenig, P. (1989). Echtzeitanalyse von Orofacialen Bewegungen mit Hilfe der Elektromagnetischen Artikulographie. Biomedizinische Technik, 34, 126-130.

Selkirk, E. (1984). Phonology and syntax: The relation between sound and structure. Cambridge, MA: MIT Press.

Shattuck-Hufnagel, S., \& Turk, A. E. (1996). A prosody tutorial for investigators of auditory sentence processing. Journal of Psycholinguistic Research, 25(2), 193-247.

Sheskin, D. J. (2000). Handbook of parametric and nonparametric statistical procedures (2nd ed.). Boca Raton: Chapman \& Hall/CRC.

Shields, J. L., McHugh, A., \& Martin, J. G. (1974). Reaction time to phoneme targets as a function of rhythmic cues in continuous speech. Journal of Experimental Psychology, 102, 250-255.

Shin, J. (1997). Consonantal production and coarticulation in Korean. Ph.D. Dissertation, University of London.

Silverman, K., Beckman, M., Pitrelli, J., Ostendorf, M., Wightman, C., Price, P., Pierrehumbert, J., \& Hirschberg, J. (1992). TOBI: A standard for labeling English prosody. In Proceedings of the 1992 international conference on spoken language processing, Vol. 2 (pp. 867-870). 
Stevens, K. (1972). The quantal nature of speech: Evidence from articulatory-acoustic data. In P. B. Denes, \& E. E. David Jr.(Eds.), (Eds.), Human communication: A unified view (pp. 51-66). New York: McGraw-Hill.

Stevens, K. (1989). On the quantal nature of speech. Journal of Phonetics, 17, 3-45.

Tabain, M. (2003). Effects of prosodic boundary on /aC/ sequences: Acoustic results. Journal of the Acoustical Society of America, 113, 516-531.

Tuller, B., Shao, S., \& Kelso, J. A. S. (1990). An evaluation of an alternating magnetic field device for monitoring tongue movements. Journal of the Acoustical Society of America, 88, 674-679.

Westbury, J. R. (1994). On coordinate systems and the representation of articulatory movements. Journal of the Acoustical Society of America, 95(4), 2271-2273.

Wightman, C. W., Shattuck-Hufnagel, S., Ostendorf, M., \& Price, P. J. (1992). Segmental durations in the vicinity of prosodic phrase boundaries. Journal of the Acoustical Society of America, 91, 1707-1717. 